\title{
Development and Validation of the Delaying Gratification Inventory
}

\author{
Michael Hoerger \\ University of Rochester Healthcare Decision-Making Group and \\ Central Michigan University
}

\author{
Stuart W. Quirk and Nathan C. Weed \\ Central Michigan University
}

\begin{abstract}
Deficits in gratification delay are associated with a broad range of public health problems, such as obesity, risky sexual behavior, and substance abuse. However, 6 decades of research on the construct has progressed less quickly than might be hoped, largely because of measurement issues. Although past research has implicated 5 domains of delay behavior, involving food, physical pleasures, social interactions, money, and achievement, no published measure to date has tapped all 5 components of the content domain. Existing measures have been criticized for limitations related to efficiency, reliability, and construct validity. Using an innovative Internet-mediated approach to survey construction, we developed the 35-item 5-factor Delaying Gratification Inventory (DGI). Evidence from 4 studies and a large, diverse sample of respondents $(N=10,741)$ provided support for the psychometric properties of the measure. Specifically, scores on the DGI demonstrated strong internal consistency and test-retest reliability for the 35 -item composite, each of the 5 domains, and a 10 -item short form. The 5 -factor structure fit the data well and had good measurement invariance across subgroups. Construct validity was supported by correlations with scores on closely related self-control measures, behavioral ratings, Big Five personality trait measures, and measures of adjustment and psychopathology, including those on the Minnesota Multiphasic Personality Inventory-2-Restructured Form. DGI scores also showed incremental validity in accounting for well-being and health-related variables. The present investigation holds implications for improving public health, accelerating future research on gratification delay, and facilitating survey construction research more generally by demonstrating the suitability of an Internetmediated strategy.
\end{abstract}

Keywords: impulsivity, delay discounting, self-control, Internet research, test construction

Supplemental materials: http://dx.doi.org/10.1037/a0023286.supp

Delaying gratification refers to the tendency to forego strong immediate satisfaction for the sake of salient long-term rewards. Although most develop a burgeoning capacity to delay gratification by early adolescence, adulthood is marked by substantial individual differences in delay behavior (Lee, Lan, Wang, \& Chiu, 2008). National Institutes of Health (2009, p. 2) guidelines identify gratification delay as having a nontrivial impact on public health, with 6 decades of research linking poor gratification delay to societal problems, including obesity, substance abuse, risky sexual behavior, psychopathology, consumer debt, criminality, and low educational attainment (Baumeister, Vohs, \& Tice, 2007; Bembenutty \& Karabenick, 2004; DeWall, Baumeister, Stillman, \& Galliot, 2007; Gottdiener, Murawski, \& Kucharski, 2008; Seeyave et

This article was published Online First April 11, 2011

Michael Hoerger, University of Rochester Healthcare Decision-Making Group; Department of Psychology, Central Michigan University. Stuart W. Quirk and Nathan C. Weed, Department of Psychology, Central Michigan University.

This research was supported by the Central Michigan University Dissertation Research Support Grant and by Grant T32MH018911 from the National Institutes of Health.

Correspondence concerning this article should be addressed to Michael Hoerger, University of Rochester Medical Center, Department of Psychiatry, 300 Crittenden Boulevard, Rochester, NY 14642. E-mail: hoerger.urmc@gmail.com al., 2009; Wulfert, Safren, Brown, \& Wan, 1999). Despite its importance, research on gratification delay has not progressed as quickly as might be hoped largely because of measurement limitations and inconsistent findings (Baumeister et al., 2007; Lee et al., 2008; Mauro \& Harris, 2000; McLeish \& Oxoby, 2007; Richards, Zhang, Mitchell, \& de Wit, 1999; Smith \& Hantula, 2008). We put forth a framework for conceptualizing gratification delay, examine the relative merits of available measurement strategies, and use a novel, Internet-mediated approach to survey development.

\section{Theoretical Framework}

Historically, terms like gratification delay, self-regulation, selfcontrol, impulsivity, and ego resiliency have often been used interchangeably or inconsistently (Funder, Block, \& Block, 1983; Gailliot et al., 2007; Lee et al., 2008; Mauro \& Harris, 2000; Mischel, Cantor, \& Feldman, 1996; Mischel \& Gilligan, 1964; Muraven, Baumeister, \& Tice, 1999), and subtle distinctions between constructs have been ignored (see Figure A1, Appendix A, in the supplemental materials). Authoritative reviews emphasize that under the umbrella of self-regulation exists self-control (Baumeister et al., 2007; Gailliot et al., 2007), which can be understood as a continuum of three constructs, with gratification delay occupying conceptual space between impulse control and ego resiliency (Funder \& Block, 1989). Delay of gratification is similar to impulse control in that both involve resisting strong 
rewards, can occasionally be disadvantageous, and have traitlike features (Baumeister \& Vohs, 2004; Funder \& Block, 1989; Funder et al., 1983; Gottdiener et al., 2008; Ramanathan \& Menon, 2006). Alternately, gratification delay is similar to ego resiliency (but different from impulse control) in that both require a future time orientation, involve carefully weighing consequences, and have ability features (Bembenutty \& Karabenick, 2004; Funder \& Block, 1989; Mischel, Shoda, \& Peake, 1988; Twenge, Catanese, \& Baumeister, 2003). Thus, operationalizing gratification delay involves posing choices between evocative immediate rewards and salient long-term consequences.

In addition to synthesizing past research to identify a clear definition of gratification delay, there is a need to articulate the content domain of the construct. We examined five domains of gratification delay, involving (a) food, (b) physical pleasures, (c) social interactions, (d) money, and (e) achievement. Baumeister et al. (2007, Box 1, p. 353) described a somewhat similar set of five domains of behavior with evolutionary significance that were vulnerable to ego depletion. Further, several additional studies have described at least two of the hypothesized five factors of delay behavior (see Table B1 in the supplemental materials; e.g., Baumeister, Heatherton, \& Tice, 1994; Bembenutty \& Karabenick, 1998, 2004; Lee et al., 2008; Mischel et al., 1988; Ramanathan \& Williams, 2007). This investigation was designed to develop a scale measuring individual differences in the five domains of gratification delay that have received attention in past research.

\section{Measurement Strategies}

In 6 decades, three types of measures have mainly been used to assess gratification delay: early performance-based strategies, Mischel's paradigm, and delay discounting tasks. Performance measures have included the number of human movement responses on the Rorschach, maze and tracing tasks, time estimation, the Stroop, and stop-signal tasks. In addition to being time consuming, these measures have a disjointed theoretical relationship to gratification delay (Rapaport, 1951) and have demonstrated poor evidence of construct validity (Nederkoorn, Smulders, Havermans, Roefs, \& Jansen, 2006; Singer, Meltzoff, \& Goldman, 1952; Wormith \& Hasenpusch, 1979).

Given these pitfalls, Mischel (Funder et al., 1983; Mischel, 1958; Mischel \& Ayduk, 2002; Mischel et al., 1988) explored the behavioral decision-making paradigm as a more suitable method for assessing delay of gratification. As reviewed by Mischel (1996), classic studies involved young children choosing between receiving one marshmallow immediately or two marshmallows after a brief (e.g., $20 \mathrm{~min}$ ) delay period. Although this constitutes a clear operationalization of the construct, limitations of this strategy include narrow coverage of the content domain, inefficiency, and low suitability to adult participants. Of greater concern, this paradigm often relies on one or a very limited number of choices, yielding a dichotomous indicator of delay behavior, which attenuates reliability and validity estimates (Funder et al., 1983; Mauro \& Harris, 2000; Mischel, 1958; Wormith \& Hasenpusch, 1979). Multiple observations of delay behavior yield stronger results (Funder \& Block, 1989; Mischel \& Gilligan, 1964), but narrow content domain and age limitations remain.

First designed for animal studies, delay discounting tasks have recently gained popularity for assessing gratification delay in human adults (e.g., Reynolds, 2006). Using real or hypothetical monetary reinforcers, the approach examines changes in response curves, or other metrics, as a result of greater delays in reinforcement. The tasks consist of a lengthy series of items that ask participants to choose, for example, between $\$ 50$ today and $\$ 90$ tomorrow. The delay period is incrementally increased until the examinee opts for the immediate reward, signaling a maximum delay period. Task limitations include being time consuming, covering only one aspect of the content domain (i.e., money), and being costly if real reinforcers are used. Also, there is stronger evidence for predictive validity (Reynolds, 2006; Shamosh et al., 2008) than for construct validity (McLeish \& Oxoby, 2007; Richards et al., 1999; Smith \& Hantula, 2008; Wormith \& Hasenpusch, 1979). This led Reynolds (2006) to call for "a better understanding of what is being assessed with these measures" (p. 665), as they may tap working memory, logical reasoning, withdrawal sensitivity, or other important constructs beyond gratification delay.

Survey methodology provides practical and psychometric benefits over alternative strategies. The practical advantages of being able to recruit large samples of adults quickly and inexpensively have been shown in studies on the three published scales, including the 12-item Deferment of Gratification Questionnaire (Ray \& Najman, 1986), the 10-item Academic Delay of Gratification Scale (Bembenutty \& Karabenick, 1998), and the 22-item Multidimensional Delay of Gratification Scale (Ward, Perry, Woltz, \& Doolin, 1989). Yet, existing scales have room for improvement in content validity and score reliability. Specifically, no published scale has explicitly addressed the entire content domain relevant to measuring gratification delay. The Deferment of Gratification Questionnaire was crafted without apparent review of the broad content domain of gratification delay, and the Academic Delay of Gratification Scale focuses on achievement. The Multidimensional Delay of Gratification Scale was intended to measure two sociopolitical aspects of gratification delay in South African Apartheid-era opposition, but the factor structure was unsupported, and additional domains were not included. Internal consistency reliability for scores on the three measures has fallen short of expectations, ranging from .68 to .74 , with potential culprits including survey brevity and difficult item wording. Our goal was to extend the practical advantages of surveys by developing a five-factor measure of gratification delay that produces scores of high reliability.

\section{Internet Methodology}

The growth of publicly available Web-based psychology studies suggests potential avenues for scale development research. Compared with traditional laboratory studies conducted in person with undergraduates, Internet-mediated research permits several advantages, including increased sampling efficiency, greater sample heterogeneity, decreased research time, and lower costs (Hoerger, 2010; Hoerger \& Currell, in press). For example, two Web studies of individual differences have surpassed 100,000 participants (Nosek, Banaji, \& Greenwald, 2002; Srivastava, John, Gosling, \& Potter, 2003). Large, heterogeneous samples are particularly alluring for test construction projects. Power stabilizes item-total correlations, allowing the best set of items to be selected from a larger item pool, and sample heterogeneity improves external validity. In contrast, overreliance on small convenience samples can threaten 
cross-sample reliability estimates (e.g., the Subtle items of the Minnesota Multiphasic Personality Inventory; Graham, 2006).

The upside of Internet-mediated studies can substantially overshadow risks. Foremost, early methodological concerns about Web-based research (e.g., measurement inequivalence) have not been borne out by data (De Beuckelaer \& Lievens, 2009; Gosling, Vazire, Srivastava, \& John, 2004). Further, technico-ethical issues, such as confidentiality and consent, can be handled effectively for low-risk studies (Hoerger \& Currell, in press; Kraut et al., 2004). One realistic concern is that the public is unlikely to complete a lengthy battery of validity measures (Krug, 2005). As such, we initiated a two-step approach to development and validation. During development, the survey was to be administered to a broad public sample, optimizing evidence for reliability and factor structure. Validation evidence from a lengthier set of measures was to come primarily from traditional convenience samples of undergraduates, who are less deterred by study length (Hoerger, 2010).

\section{Present Investigation}

The present investigation involved four Internet-mediated studies on the development and validation of the Delaying Gratification Inventory (DGI). In Studies 1 and 2, we focused on scale development, using a large, diverse sample of adults worldwide. These studies were designed to provide evidence regarding internal consistency reliability, factor structure, and measurement invariance, with ancillary analyses also providing provisional evidence of test-retest reliability and construct validity. In Study 1, we administered a large pool of items in order to craft the final 35 -item scale, and Study 2 was a cross-sample replication and extension. In Studies 3 and 4, we focused on validation, using smaller convenience samples of undergraduates. Study 3 provided evidence of test-retest reliability, construct validity, and incremental validity, whereas in Study 4, we focused exclusively on validity evidence involving adjustment and psychopathology correlates of the resulting survey's scores.

\section{Studies 1 and 2}

\section{Methods}

Procedures. Large, worldwide samples participated in pilot testing and Studies 1 and 2 through the Web. We rationally developed a large pool of items, based on our five-factor framework, and these items were piloted extensively online to hundreds of participants. On the basis of participants' anonymous feedback, we removed or modified items that were potentially confusing or biased. In combination with psychometric evidence, the item pool was iteratively revised, ultimately resulting in a manageable set of 70 items measuring the five domains of gratification delay. This item pool was administered online during Study 1. The results of Study 1 were used to devise the 35 -item DGI, which was administered online in Study 2. These studies were intended to provide replicable evidence of internal consistency, factor structure, and measurement invariance. Also, a small set of additional items was administered in Study 2 to provide initial evidence of construct validity, and test-retest reliability was examined for a subset of participants completing the measure twice.
These studies were designed to minimize cost, optimize participant recruitment, and meet high ethical standards for Internetmediated research (Hoerger \& Currell, in press). The study website was accessible through research sites, search engines, relevant Wikipedia pages, Facebook, discussion forums, and blogs. After entering the site, participants could access the investigator's contact information, relevant research articles, institutional review board approval documentation, frequently asked questions, and an online consent form to begin participation. After completing the survey, participants received additional study information, innocuous tailored personality feedback based on their survey responses (coded with Perl common gateway interface), and optional links for providing anonymous feedback and entering a cash drawing for $\$ 100$.

Numerous procedures were used to reduce repeat or invalid response contamination. For most browsers, JavaScript ensured that all questions were answered prior to form submission. To guard against multiple submissions, participants were asked directly whether they had participated previously, and the top of the survey included an unusual picture to assist their memory of the site (a picture of an okapi, a zebra-like animal). We also tracked partial Internet protocol (IP) addresses (see Hoerger \& Currell, in press), which are standard IP addresses but with the leading digit removed, thereby ensuring some tracking capability while better ensuring anonymity. Response validity items were also embedded within survey content. Finally, participants had the incentive of responding honestly to gain realistic personality feedback.

Measures. All study measures were completed in English. Participants indicated whether they had completed the survey previously and optionally provided demographic information, including gender, age, ethnicity (based on the 2000 U.S. Census categories), location (all U.S. states, Canada, Mexico, Europe, Asia, Australia, South America, or Africa), highest grade completed, and high school grade point average.

DGI. The 35-item scale (see Table 1) yields gratification delay scores for five domains (food, physical pleasures, social interactions, money, and achievement), a 35-item composite (DGI35), and a 10-item short-form composite (DGI-10). Seventeen items are reverse-coded, and participants reported how well each item described them, using a scale from 1 (strongly disagree) to 5 (strongly agree).

Personality and behavioral tendencies. In Study 2 only, participants rated themselves on 30 single-item personality trait descriptors (e.g., "Neuroticism: to feel sad, worried, anxious, nervous, depressed, moody, frustrated, irritated, and out of control") and 17 single-item behavioral tendencies (e.g., "I pay bills on time"); see the Results section for a complete listing. Participants rated how well traits described them on a scale from 1 (below average) to 9 (above average) and rated behavioral tendencies on a scale from 1 (never) to 5 (always). Very brief measures have shown merit for studies in which hypothesized correlations were sizeable (Donnellan, Oswald, Baird, \& Lucas, 2006; Wanous, Reichers, \& Hudy, 1997), and brevity was necessary for maintaining participant recruitment (Hoerger, 2010; Krug, 2005).

Participants. Data from a large sample of survey respondents $(n=10,241)$ in Studies 1 and 2 were cleaned to remove invalid responses prior to core analyses. Reasons for exclusion included missing data, invalid response sets, repeat participation as indicated by self-report, repeat participation as indicated by a recurrent 
Table 1

Delaying Gratification Inventory (DGI) Items by Domain

\begin{tabular}{|c|c|}
\hline Item & Text \\
\hline \multicolumn{2}{|r|}{ Food } \\
\hline 1 & I can resist junk food when I want to. \\
\hline 6 & $\begin{array}{l}\text { I would have a hard time sticking with a special, } \\
\text { healthy diet. }\end{array}$ \\
\hline 11 & $\begin{array}{l}\text { If my favorite food were in front of me, I would have a } \\
\text { difficult time waiting to eat it. }\end{array}$ \\
\hline 16 & $\begin{array}{l}\text { It is easy for me to resist candy and bowls of snack } \\
\text { foods. }\end{array}$ \\
\hline 21 & Sometimes I eat until I make myself sick. ${ }^{a}$ \\
\hline 26 & $\begin{array}{l}\text { I have always tried to eat healthy because it pays off in } \\
\text { the long run. }\end{array}$ \\
\hline 31 & $\begin{array}{l}\text { Even if I am hungry, I can wait until it is meal time } \\
\text { before eating something. }\end{array}$ \\
\hline \multicolumn{2}{|r|}{ Physical } \\
\hline 2 & I am able to control my physical desires. \\
\hline 7 & $\begin{array}{l}\text { I like to get to know someone before having a physical } \\
\text { relationship. }\end{array}$ \\
\hline 12 & $\begin{array}{l}\text { My habit of focusing on what "feels good" has cost me } \\
\text { in the long run." }\end{array}$ \\
\hline 17 & $\begin{array}{l}\text { I have given up physical pleasure or comfort to reach } \\
\text { my goals. }\end{array}$ \\
\hline 22 & $\begin{array}{l}\text { I prefer to explore the physical side of romantic } \\
\text { involvements right away. }\end{array}$ \\
\hline 27 & $\begin{array}{l}\text { When faced with a physically demanding chore, I } \\
\text { always tried to put off doing it. }{ }^{a, b}\end{array}$ \\
\hline 32 & $\begin{array}{l}\text { I have lied or made excuses in order to go do something } \\
\text { more pleasurable. }\end{array}$ \\
\hline
\end{tabular}

\section{Social}

3 I hate having to take turns with other people. ${ }^{\text {a }}$

8 Usually I try to consider how my actions affect others.

13 I think that helping each other benefits society.

18 I try to consider how my actions will affect other people in the long-term. ${ }^{\mathrm{b}}$

23 I do not consider how my behavior affects other people. $^{\mathrm{a}, \mathrm{b}}$

28 I value the needs of other people around me.

33 There is no point in considering how my decisions affect other people.

\begin{tabular}{|c|c|}
\hline & Money \\
\hline 4 & $\begin{array}{l}\text { When I am able to, I try to save away a little money in } \\
\text { case an emergency should arise. }\end{array}$ \\
\hline 9 & It is hard for me to resist buying things I cannot afford. \\
\hline 14 & I try to spend my money wisely. ${ }^{\mathrm{b}}$ \\
\hline 19 & I cannot be trusted with money. \\
\hline 24 & $\begin{array}{l}\text { When someone gives me money, I prefer to spend it } \\
\text { right away. }\end{array}$ \\
\hline 29 & I manage my money well. \\
\hline 34 & I enjoy spending money the moment I get it. ${ }^{a}$ \\
\hline
\end{tabular}

\section{Achievement}

5 I worked hard in school to improve myself as a person. 10 I have tried to work hard in school so that I could have a better future.

15 In school, I tried to take the easy way out. ${ }^{\mathrm{a}}$

20 I am capable of working hard to get ahead in life.

25 I cannot motivate myself to accomplish long-term goals. ${ }^{\mathrm{a}, \mathrm{b}}$

30 I have always felt like my hard work would pay off in the end. ${ }^{\mathrm{b}}$

35 I would rather take the easy road in life than get ahead. ${ }^{\mathrm{a}}$

${ }^{\mathrm{a}}$ Indicates reverse-coded item. ${ }^{\mathrm{b}}$ Indicates inclusion on DGI-10 short form composite. partial IP address with matching demographics, and accidental duplicate form submissions. Of the responses, 95\% were retained as valid (Study 1: 1,900 of 1,982; Study 2: 7,771 of 8,259). Participants were diverse in terms of age $(M=30.6, S D=10.9$ years), ethnicity, location, and education level (see Table 2).

\section{Results and Discussion}

The results of Study 1 were used to develop a reliable 35-item scale, covering the five domains of gratification delay (for itemtotal correlations, see Tables B2 and B3 in the supplemental materials). Scale means, standard deviations, internal consistency reliabilities, and intercorrelations are shown for all U.S. participants from both studies in Table 3 (and are separated by study, gender, and location in Tables B4 through B8 in the supplemental materials). Across subgroups, internal consistency reliability was strong for scores on the DGI-35 composite scale $(\alpha \geq .90)$ and good for scores on the DGI-10 short form ( $\alpha \geq$.77). Thus, both the

Table 2

Demographic Characteristics for Participants in Studies 1 and 2

\begin{tabular}{|c|c|c|c|c|}
\hline \multirow[b]{2}{*}{ Demographic characteristic } & \multicolumn{2}{|c|}{ Study 1} & \multicolumn{2}{|c|}{ Study 2} \\
\hline & $n$ & $\%$ & $n$ & $\%$ \\
\hline \multicolumn{5}{|l|}{ Age } \\
\hline $18-19$ & 322 & 17.5 & 870 & 11.7 \\
\hline $20-29$ & 808 & 44.0 & 3,296 & 44.1 \\
\hline $30-39$ & 369 & 20.1 & 1,805 & 24.2 \\
\hline $40-49$ & 215 & 11.7 & 917 & 12.3 \\
\hline $50-59$ & 100 & 5.4 & 452 & 6.1 \\
\hline $60-69$ & 21 & 1.1 & 114 & 1.5 \\
\hline $70+$ & 3 & 0.2 & 12 & 0.2 \\
\hline \multicolumn{5}{|l|}{ Gender } \\
\hline Female & 888 & 47.1 & 3,578 & 46.3 \\
\hline Male & 997 & 52.9 & 4,142 & 53.7 \\
\hline \multicolumn{5}{|l|}{ Race/ethnicity } \\
\hline White and non-Latino & 1,401 & 74.4 & 5,770 & 74.6 \\
\hline Black or African descent & 66 & 3.5 & 237 & 3.1 \\
\hline Asian descent & 210 & 11.1 & 919 & 11.9 \\
\hline Hispanic or Latino of any race & 71 & 3.8 & 293 & 3.8 \\
\hline Biracial or Multiracial & 87 & 4.6 & 285 & 3.7 \\
\hline Other & 49 & 2.6 & 226 & 2.9 \\
\hline \multicolumn{5}{|l|}{ Location } \\
\hline United States & 1,178 & 62.9 & 3,747 & 49.0 \\
\hline Canada & 146 & 7.8 & 412 & 5.4 \\
\hline Mexico & 8 & 0.4 & 15 & 0.2 \\
\hline Europe & 329 & 17.6 & 1,088 & 14.2 \\
\hline Asia & 103 & 5.5 & 402 & 5.3 \\
\hline Australia & 84 & 4.5 & 1,879 & 24.6 \\
\hline South America & 18 & 1.0 & 56 & 0.7 \\
\hline Africa & 7 & 0.4 & 51 & 0.7 \\
\hline \multicolumn{5}{|l|}{ Education level (U.S. only) } \\
\hline Doctoral degree & 63 & 5.4 & 264 & 7.1 \\
\hline Master's degree & 160 & 13.7 & 668 & 17.9 \\
\hline Bachelor's degree & 296 & 25.3 & 966 & 25.9 \\
\hline Some college & 423 & 36.2 & 1,214 & 32.6 \\
\hline High school diploma & 162 & 13.9 & 425 & 11.4 \\
\hline Not a high school graduate & 65 & 5.6 & 192 & 5.1 \\
\hline
\end{tabular}

Note. For Study $1, n=1,900$; however, responses were missing for age $(n=62)$, gender $(n=15)$, ethnicity $(n=16)$, location $(n=27)$, education level $(n=9)$, and grade point average $(n=57)$. For Study $2, n=7,771$, but responses were missing for age $(n=305)$, gender $(n=51)$, ethnicity $(n=41)$, location $(n=121)$, education level $(n=18)$, and grade point average $(n=134)$. 
Table 3

Delaying Gratification Inventory (DGI) Scale Score Properties in Studies 1 and 2 for All U.S. Participants

\begin{tabular}{lccccccccc}
\hline \multicolumn{1}{c}{ Scale } & $M$ & $S D$ & 1 & 2 & 3 & 4 & 5 & 6 & 7 \\
\hline 1. Food & 22.3 & 5.8 & $(.75)$ & & & & & & \\
2. Physical & 22.8 & 5.2 & .43 & $(.71)$ & & & & & \\
3. Social & 29.3 & 4.4 & .25 & .43 & $(.81)$ & & & & \\
4. Money & 26.8 & 6.4 & .36 & .50 & .33 & $(.89)$ & & & \\
5. Achievement & 26.7 & 6.0 & .33 & .58 & .43 & .44 & $(.85)$ & & \\
6. DGI-10 & 36.3 & 6.9 & .59 & .73 & .60 & .66 & .75 & $(.79)$ & \\
7. DGI-35 & 127.9 & 20.2 & .66 & .81 & .63 & .75 & .77 & .92 & $(.91)$ \\
\hline
\end{tabular}

Note. $\quad N=4,925$. Alphas are indicated in parentheses.

long and short forms produced reliable measurements of general individual differences in gratification delay. Across participant groups, subscale scores also had good reliability $(\alpha=.69-.89)$ and were modestly intercorrelated $(r=.23-.60)$. Item-level statistics for the DGI-35 were stable across samples, and items loaded relatively uniquely on their designated domains. As expected, the five domains had modestly overlapping variance but also accounted for unique aspects of gratification delay.

Internal consistency and domain intercorrelations were similar across gender and participant location, but some mean differences were present (see Tables B5 through B8 in the supplemental materials). Specifically, female participants scored slightly higher than male participants in terms of composite gratification delay (DGI-35: $d=0.17-0.21$ ) and across most domains, with the greatest female advantage observed in the achievement domain $(d=0.41-0.42)$. In contrast, male participants reported greater gratification delay in the food domain $(d=0.22-0.28)$. In terms of location, U.S. participants differed from international participants mainly in terms of greater delay of gratification in the achievement domain $(d=0.25-0.32)$. Observed demographic differences were present but generally small to moderate in size and consistent with prior research.

Confirmatory factor analysis supported the hypothesized fivefactor model, which was robustly upheld across demographic groups. Confirmatory factor analysis model fit was examined with LISREL 8.80, using Satorra and Bentler's (1988) method, which corrects for interval data. To adequately characterize model fit, most researchers report several fit statistics, such as the comparative fit index, the normed fit index, root-mean-square error of approximation, standardized root mean residual, the Akaike information criterion, chi-square, and the ratio of chi-square to degrees of freedom $\left(\chi^{2} / d f\right)$. First, we examined model fit for the entire sample of Study 1 and 2 participants. The hypothesized five-factor model (for a diagram, see Figure A2 in the supplemental materials) fit the data well: comparative fit index $=.964$, normed fit index $=$ .962 , root-mean-square error of approximation $=.057$, standardized root mean residual $=.058$, Akaike information criterion $=$ 18,031 , Satorra-Bentler scaled $\chi^{2}(550)=17,871, p<.001$, and $\chi^{2} / d f=32.49$. Because the physical and achievement domains were the most related, we compared our theory-driven model to a four-factor model combining these domains. We also used multigroup confirmatory factor analysis to compare the five-factor structure by study sample, gender, and participant location. The four-factor model was rejected because it offered no appreciable improvement in fit, and the five-factor model was found to have strong structural, factor, and variance-covariance invariance across samples, genders, and participant locations (see Table B9 in the supplemental materials).

Table 4 shows initial validity evidence for DGI scores in Study 2. In general, scores correlated highly with those from closely related constructs, such as self-discipline, self-control, conscientiousness, and moderation. DGI composite scores were also strongly related to health $(r=.40-.43)$ and well-being $(r=$ .43-.46), and scores increased slightly with age and educational attainment. Patterns of correlations varied in theoretically meaningful ways across domains of gratification delay. Among the five domains, the food domain scores correlated most highly with moderation/immoderation, health, anxiety, perceived attractiveness, somatization, fast food consumption, thinking about food, exercise, soda drinking, and watching television. Notable correlates of the physical domain include sensation seeking, reported lying, rebelliousness, rule breaking, sexual thoughts, impulse control, partying excessively, neuroticism, anxiety, excitement seeking, smoking cigarettes, risk taking, gambling, and Machiavellianism. The social domain was most distinct, relating to altruism, agreeableness, helping other people, prudence, patience, anger, openness to experience, comprehension, and discussing intellectual topics. Money domain scores were linked to extravagance, buying unneeded purchases, self-control, paying bills on time, smoking cigarettes, checking financial news, and gambling. Finally, the achievement score was predictive of achievement striving, diligence, self-discipline, conscientiousness, well-being, depression, high school grade point average, education level, reading books, extraversion, and perceived intelligence. Correlations between DGI-35 scores and the traits and behavioral tendencies listed in Table 4 varied minimally across gender, location, and participant age decade (average magnitude of deviation in $r$ across subgroups was .03). In summary, the food domain is related to delay behavior involving food, health, and activity level; the physical domain is related to sensation seeking, drives, and thrills; the social domain is related to altruistic and prosocial behaviors; the money domain is related to day-to-day financial management; and the achievement domain is related to conscientiousness and achievement striving. The validity of score interpretations were consistent across demographic groups studied. Thus, promising initial findings implicated the need for more detailed follow-up studies. 
Table 4

Correlations Between Delaying Gratification Inventory (DGI) Scores, Demographics, Trait Descriptor Ratings, and Behavioral Tendency Ratings in Study 2

\begin{tabular}{|c|c|c|c|c|c|c|c|}
\hline Measure & Food & Physical & Social & Money & Achievement & DGI-10 & DGI-35 \\
\hline \multicolumn{8}{|l|}{ Demographic } \\
\hline Age & .05 & .14 & .15 & .10 & .08 & .12 & .14 \\
\hline High school GPA & .07 & .23 & .16 & .27 & .34 & .28 & .30 \\
\hline Education level & .03 & .16 & .19 & .21 & .25 & .23 & .23 \\
\hline \multicolumn{8}{|l|}{ Trait descriptors } \\
\hline Moderation & .53 & .52 & .29 & .42 & .37 & .56 & .59 \\
\hline Self-discipline & .37 & .53 & .27 & .37 & .57 & .59 & .59 \\
\hline Diligence & .32 & .50 & .29 & .33 & .63 & .59 & .58 \\
\hline Conscientiousness & .32 & .49 & .30 & .36 & .56 & .57 & .57 \\
\hline Self-control & .34 & .47 & .28 & .53 & .37 & .51 & .56 \\
\hline Extravagance & -.28 & -.40 & -.21 & -.74 & -.29 & -.48 & -.55 \\
\hline Immoderation & -.53 & -.48 & -.22 & -.40 & -.34 & -.50 & -.55 \\
\hline Achievement striving & .24 & .40 & .29 & .32 & .64 & .52 & .53 \\
\hline Well-being & .26 & .36 & .29 & .25 & .41 & .46 & .43 \\
\hline Prudence & .17 & .34 & .38 & .32 & .29 & .36 & .41 \\
\hline Patience & .28 & .32 & .34 & .29 & .24 & .35 & .40 \\
\hline Perceived health & .36 & .30 & .18 & .24 & .33 & .43 & .40 \\
\hline Impulse control & .30 & .33 & .27 & .26 & .25 & .36 & .39 \\
\hline Rebelliousness & -.13 & -.39 & -.31 & -.27 & -.32 & -.32 & -.39 \\
\hline Agreeableness & .16 & .29 & .46 & .19 & .30 & .34 & .37 \\
\hline Neuroticism & -.26 & -.33 & -.21 & -.23 & -.28 & -.36 & -.36 \\
\hline Depression & -.25 & -.28 & -.18 & -.22 & -.30 & -.35 & -.34 \\
\hline Anger & -.24 & -.27 & -.30 & -.21 & -.22 & -.30 & -.34 \\
\hline Sensation seeking & -.08 & -.44 & -.20 & -.26 & -.21 & -.25 & -.33 \\
\hline Altruism & .11 & .21 & .53 & .07 & .26 & .30 & .30 \\
\hline Anxiety & -.25 & -.25 & -.16 & -.19 & -.22 & -.29 & -.30 \\
\hline Perceived attractiveness & .33 & .16 & .08 & .14 & .21 & .29 & .26 \\
\hline Somatization & -.20 & -.16 & -.13 & -.18 & -.15 & -.23 & -.23 \\
\hline Comprehension & .14 & .13 & .21 & .14 & .17 & .21 & .21 \\
\hline Excitement seeking & .00 & -.24 & -.19 & -.21 & -.12 & -.14 & -.21 \\
\hline Perceived intelligence & .14 & .12 & .15 & .15 & .17 & .20 & .20 \\
\hline Risk taking & .01 & -.22 & -.19 & -.20 & -.10 & -.13 & -.19 \\
\hline Openness to experience & .12 & .10 & .28 & .07 & .15 & .19 & .19 \\
\hline Machiavellianism & -.01 & -.16 & -.15 & -.14 & -.08 & -.09 & -.14 \\
\hline Extraversion & .10 & .05 & .13 & -.05 & .18 & .15 & .11 \\
\hline \multicolumn{8}{|l|}{ Behavioral tendency } \\
\hline Buy unneeded purchases & -.32 & -.33 & -.20 & -.58 & -.23 & -.41 & -.48 \\
\hline Lie or hide the truth & -.23 & -.44 & -.32 & -.32 & -.35 & -.41 & -.46 \\
\hline Pay bills on time & .19 & .32 & .19 & .47 & .32 & .40 & .43 \\
\hline Bend or break the rules & -.11 & -.35 & -.27 & -.29 & -.27 & -.28 & -.36 \\
\hline Eat fast food & -.37 & -.23 & -.15 & -.25 & -.17 & -.34 & -.33 \\
\hline Exercise & .32 & .25 & .13 & .19 & .27 & .38 & .32 \\
\hline Help other people & .12 & .26 & .44 & .08 & .31 & .30 & .32 \\
\hline Party excessively & -.08 & -.33 & -.14 & -.26 & -.17 & -.20 & -.27 \\
\hline Drink pop/soda & -.28 & -.17 & -.14 & -.19 & -.12 & -.26 & -.25 \\
\hline Smoke cigarettes & -.06 & -.23 & -.11 & -.25 & -.18 & -.22 & -.23 \\
\hline Think about sex & -.05 & -.35 & -.13 & -.13 & -.15 & -.17 & -.22 \\
\hline Read books & .11 & .19 & .19 & .10 & .20 & .21 & .21 \\
\hline Check financial news & .16 & .13 & .06 & .23 & .16 & .23 & .21 \\
\hline Think about food & -.39 & -.13 & -.02 & -.13 & -.05 & -.14 & -.21 \\
\hline Gamble & -.08 & -.19 & -.16 & -.16 & -.15 & -.17 & -.20 \\
\hline Discuss intellectual topics & .12 & .09 & .19 & .13 & .14 & .18 & .18 \\
\hline Watch television shows & -.18 & -.10 & -.06 & -.08 & -.06 & -.12 & -.13 \\
\hline
\end{tabular}

Note. $n=7,771$. To facilitate visual inspection, correlations greater than magnitude $r=.30$ are in bold, although all correlations greater than magnitude $r=.02$ are statistically significant $(p<.05)$. GPA $=$ grade point average.

Finally, we conducted an exploratory analysis to examine testretest reliability. Among all participants, 151 self-reported having completed the measure more than once (repeat responses excluded in previous analyses). For a subsample of them $(n=35)$, we were able to identify their first and second survey submission on the basis of their partial IP address and matching demographic characteristics. On average, the duration between testing was approximately 2 months $(M d n=51.6$ days, $M=74.7$ days, $S D=94.6$ 
days). Test-retest correlations were strong across scale scores: food $(r=.74)$, physical $(r=.84)$, social $(r=.74)$, money $(r=$ $.90)$, achievement $(r=.86)$, DGI-10 $(r=.87)$, and DGI-35 $(r=$ .90). Although a more detailed follow-up is needed, available evidence supports strong test-retest reliability of DGI scores.

Results support the utility of Web-based scale development and provide strong psychometric evidence for DGI scores. On the basis of a diverse worldwide sample of over 10,000 adult respondents, we found evidence for internal consistency reliability, test-retest reliability, a theoretically driven factor structure, measurement invariance, and construct validity. Studies 3 and 4 were designed to pick up where Study 2 left off, by examining additional validity evidence in greater depth.

\section{Study 3}

\section{Methods}

Participants and procedures. Whereas Studies 1 and 2 focused on internal consistency and factor structure, Study 3 was designed to examine test-retest reliability under more controlled circumstances, additional evidence for construct validity, and incremental validity. An undergraduate convenience sample was recruited, given the study length and lack of substantive demographic differences in gratification delay in Study 2. The study was administered in two phases, both through SurveyMonkey.com. In Phase 1, participants $(n=207)$ completed the DGI among measures for other studies; four participants were dropped because of invalid response sets. A subset of participants $(n=64)$ agreed to complete Phase 2 two months later, completing the DGI again and other measures of personality and behavior. Participants were mainly young (age: $M=19.3, S D=2.4$; standing: $76.4 \%$ freshmen), female $(65.6 \%)$, White $(93.8 \%)$, and of average academic ability (ACT: $M=22.6, S D=3.9$ ). DGI scores were unrelated to age, years in school, and gender $(p>.10)$; findings for ACT scores and other cognitive indicators are reviewed later.

Measures. Participants completed the 35-item DGI and the same single-item personality and behavior ratings used in Study 2. They also reported demographic information, including age, race, gender, high school and college grade point averages, and ACT score.

Self-control constructs. Participants completed three selfcontrol measures. The 36-item Self-Control Scale $(\alpha=.88$; Tangney et al., 2004) primarily taps impulse control but also hits loosely on delay of gratification, competencies, and conscientiousness, with items like "I am good at resisting temptation" rated on a scale from 1 (not at all) to 5 (very much). The 30-item Barratt Impulsivity Scale $(\alpha=.87$; Patton, Stanford, \& Barratt, 1995) focuses on impulse control but also taps broader aspects of selfcontrol and emotional stability. Items like "I concentrate easily" are rated on a scale from 1 (never) to 5 (always). Finally, the 10 -item Academic Delay of Gratification Scale $(\alpha=.72$; Bembenutty \& Karabenick, 1998) involves hypothetical decisions between immediate pleasures and long-term academic goals. Participants respond to items like "(A) Study a little everyday for an exam and spend less time with your friend, OR (B) Spend more time with your friends and cram just before the test?" rated on a scale from 1 (definitely choose A) to 4 (definitely choose B).
Big Five. Participants completed a 150-item version of a Big Five personality questionnaire (Goldberg et al., 2006). The scale measures neuroticism $(\alpha=.89)$, extraversion $(\alpha=.87)$, openness to experience $(\alpha=.79)$, agreeableness $(\alpha=.89)$, and conscientiousness $(\alpha=.92)$ as well as six facets for each domain. Items like "Prefer variety to routine" are rated on a scale from 1 (disagree) to 9 (agree).

\section{Results and Discussion}

Basic evidence of internal consistency, test-retest reliability, and construct validity of the DGI support initial findings from Studies 1 and 2. Specifically, internal consistency and test-retest reliabilities were strong for the DGI-35 composite $(\alpha=.88$, $r_{\text {retest }}=.88$ ) and subscale scores (average $\alpha=.77, r_{\text {retest }}=.76$ ) Thus, in addition to performing well with a diverse, worldwide sample, scores on the measure also demonstrated adequate reliability in a university convenience sample. Before examining new validity evidence, DGI scores were examined for their associations with trait descriptors and behavioral tendencies previously investigated in Study 2 (for details, see Table B10 in the supplemental materials). The pattern of correlations is notably similar to that of Study 2, providing replicable, albeit basic, evidence that DGI scores are validly interpretable, even across distinct samples.

To provide additional evidence of the validity of DGI scores, we examined correlates with several indicators of academic achievement, the Big Five personality domains and 30 underlying facets, and several closely related measures of self-control (see Table 5). Correlations with other self-control measures were generally strong, and the social and achievement domains had sizeable correlations with ACT score and grade point average. DGI scores were generally associated with greater conscientiousness and reduced neuroticism. Specific DGI domains were associated with aspects of agreeableness, extraversion, and openness. The DGI social domain was particularly associated with altruism.

Scores on the DGI also showed solid evidence for incremental validity in predicting a broad range of outcomes, including wellbeing and health-related behaviors. Specifically, we examined how well DGI scores predicted relevant outcomes over and above five closely related rival measures, including the Self-Control Scale, the Barratt Impulsivity Scale, the Academic Delay of Gratification Scale, the Big Five Agreeableness domain, and the Big Five Conscientiousness domain. Incremental validity was examined with two analytic approaches. First, we examined whether any of the DGI scores outperformed all five rival measures in predicting any of the 47 traits and behavioral tendencies listed in Table 4 (and Table B10 in the supplemental materials). Given that the DGI is composed of 35 items and the rival measures collectively consisted of 136 items, evidence for incremental validity would be notable in these statistically conservative analyses. For $57 \%$ of the trait descriptors, at least one of the DGI scales had a higher correlation than all rival scales. Significantly, for $65 \%$ of the behavioral tendencies, at least one of the DGI scales outperformed each of the five rival measures. Thus, the DGI correlated more highly with a wide range of theoretically related constructs than did a number of rival measures that consisted collectively of a much larger item pool.

Hierarchical multiple regression was used to examine incremental validity in predicting well-being and health-related variables. 
Table 5

Correlations Between Scores on the Delaying Gratification Inventory (DGI), Self-Control Measures, Cognitive Indicators, and Big Five Personality Traits in Study 3

\begin{tabular}{|c|c|c|c|c|c|c|c|}
\hline Measure & Food & Physical & Social & Money & Achievement & DGI-10 & DGI-35 \\
\hline \multicolumn{8}{|l|}{ Self-control } \\
\hline SCS & .51 & .56 & .23 & .53 & .59 & .70 & .71 \\
\hline BIS & -.35 & -.54 & -.23 & -.57 & -.54 & -.56 & -.66 \\
\hline ADOGS & .38 & .28 & .23 & .30 & .55 & .51 & .51 \\
\hline \multicolumn{8}{|l|}{ Cognitive indicators } \\
\hline ACT score & -.15 & -.04 & .25 & -.03 & .04 & .06 & .02 \\
\hline College GPA & -.12 & .10 & .34 & -.06 & .30 & .16 & .15 \\
\hline High school GPA & -.07 & .04 & .15 & .08 & .25 & .04 & .13 \\
\hline \multicolumn{8}{|l|}{ Big Five traits } \\
\hline Neuroticism & -.47 & -.31 & -.22 & -.29 & -.41 & -.49 & -.50 \\
\hline Anxiety & -.31 & -.06 & -.03 & -.10 & -.22 & -.27 & -.21 \\
\hline Anger & -.07 & -.16 & -.39 & -.18 & -.16 & -.28 & -.28 \\
\hline Depression & -.39 & -.30 & -.25 & -.11 & -.45 & -.45 & -.43 \\
\hline Self-consciousness & -.38 & -.16 & -.02 & -.07 & -.27 & -.27 & -.26 \\
\hline Immoderation & -.59 & -.38 & -.06 & -.55 & -.34 & -.52 & -.57 \\
\hline Vulnerability & -.35 & -.28 & -.13 & -.32 & -.32 & -.35 & -.41 \\
\hline Extraversion & .19 & .01 & .30 & .14 & .35 & .28 & .29 \\
\hline Friendliness & .06 & .03 & .56 & .15 & .32 & .31 & .33 \\
\hline Gregariousness & .00 & -.15 & .18 & -.09 & .06 & .03 & .00 \\
\hline Assertiveness & .26 & .04 & .07 & .15 & .23 & .19 & .23 \\
\hline Activity level & .35 & .17 & -.13 & .12 & .37 & .27 & .26 \\
\hline Excitement seeking & .14 & -.22 & -.14 & .05 & .10 & -.08 & -.01 \\
\hline Cheerfulness & .07 & .25 & .60 & .26 & .41 & .46 & .46 \\
\hline Openness & .13 & .15 & .44 & .14 & .23 & .21 & .32 \\
\hline Imagination & -.01 & -.03 & .31 & .20 & .16 & .07 & .19 \\
\hline Artistic interests & .14 & .17 & .43 & .13 & .25 & .24 & .32 \\
\hline Emotionality & -.18 & .10 & .34 & .03 & .07 & .13 & .10 \\
\hline Adventurousness & .24 & .15 & .26 & -.05 & .11 & .19 & .20 \\
\hline Intellect & .22 & .26 & .20 & .32 & .32 & .29 & .39 \\
\hline Liberalism & .06 & -.15 & .05 & -.19 & -.13 & -.19 & -.11 \\
\hline Agreeableness & .03 & .35 & .74 & .11 & .32 & .44 & .44 \\
\hline Trust & .06 & .22 & .41 & -.07 & .34 & .30 & .26 \\
\hline Morality & .03 & .39 & .50 & .12 & .34 & .40 & .39 \\
\hline Altruism & .02 & .29 & .82 & .11 & .31 & .41 & .44 \\
\hline Cooperation & .14 & .33 & .62 & .22 & .27 & .52 & .46 \\
\hline Modesty & -.05 & .12 & .42 & .07 & .09 & .11 & .18 \\
\hline Sympathy & -.09 & .23 & .62 & .03 & .09 & .26 & .24 \\
\hline Conscientiousness & .46 & .53 & .19 & .49 & .72 & .70 & .71 \\
\hline Self-efficacy & .36 & .23 & .14 & .42 & .57 & .48 & .52 \\
\hline Orderliness & .26 & .32 & -.07 & .37 & .34 & .42 & .36 \\
\hline Dutifulness & .27 & .46 & .44 & .36 & .52 & .58 & .60 \\
\hline Achievement striving & .32 & .28 & .19 & .36 & .68 & .47 & .54 \\
\hline Self-discipline & .52 & .52 & .04 & .26 & .57 & .58 & .55 \\
\hline Cautiousness & .29 & .52 & .21 & .45 & .53 & .57 & .59 \\
\hline
\end{tabular}

Note. $n=64$. To facilitate visual inspection, statistically significant correlations are in bold $(p<.05)$. SCS $=$ Self-Control Scale; BIS $=$ Barratt Impulsivity Scale; ADOGS = Academic Delay of Gratification Scale; GPA = grade point average.

Outcomes variables examined were the single-item ratings of well-being, perceived physical health, frequency of exercise, frequency of consuming fast food, and frequency of smoking cigarettes. DGI scores showed incremental validity in predicting wellbeing, fast food consumption, and smoking but not perceived health or exercise frequency. In particular, the five rival measures accounted for $34 \%$ of the variance in well-being, and the DGI achievement domain accounted for $5 \%$ of incremental variance, $\Delta R^{2}=.05, \Delta F(1,57)=4.00, p<.05$. Additionally, the five comparison measures accounted for $10 \%$ of the variance in fast food consumption, but the DGI physical domain accounted for an additional $9 \%$ of incremental variance, $\Delta R^{2}=.09, \Delta F(1,57)=$ $6.03, p<.05$. Finally, the five comparison measures explained
$15 \%$ of the variance in smoking, and the DGI money domain accounted for an additional $7 \%$ of incremental variance in reported smoking behavior, $\Delta R^{2}=.07, \Delta F(1,57)=4.89, p<.05$. Results involving incremental validity in predicting well-being and healthrelated behaviors are particularly notable given that variance in the dependent variables was likely attenuated by both the use of single-item measures as well as the relative homogeneity of the undergraduate sample on health-related variables.

In summary, Study 3 extended the two previous DGI studies in several ways. This study replicated evidence for core psychometric properties of the scale's scores, including internal consistency, test-retest reliability, and construct validity. The DGI was shown to correlate well with scores on existing survey 
measures of self-control and the Big Five, providing stronger evidence for construct validity than could be obtained in Study 2. Additionally, although the DGI correlated well with related constructs, it afforded incremental validity in predicting selfreports of well-being and health-related behaviors. Notwithstanding these strengths, evidence linking DGI scores to adjustment and psychopathology would provide greater support for its applied use.

\section{Study 4}

\section{Methods}

Participants and procedures. Study 4 was designed to gather additional evidence of the validity of DGI scores, with a greater focus on correlates related to adjustment and psychopathology. Because of proprietary restrictions, the Minnesota Multiphasic Personality Inventory-2-Restructured Form (MMPI-2-RF; Ben-Porath \& Tellegen, 2008) had to be administered in person; therefore, the study was divided into two phases. First, 293 undergraduate participants completed the majority of study measures online through SurveyMonkey.com. Second, a subset of 58 participants agreed to complete the MMPI-2-RF in a laboratory session 2 weeks later. We used validity items embedded within Phase 1 measures as well as MMPI-2-RF validity profile analysis (for guidelines, see Ben-Porath \& Tellegen, 2008) to eliminate a few invalid responders. The vast majority of Phase $1(n=286)$ and MMPI-2-RF $(n=56)$ participants responded validly and were retained for analyses. Participants were primarily young (age: $M=$ $19.7, S D=2.1$; standing: $51 \%$ freshmen), female $(65.1 \%)$, and White $(90.1 \%)$. The DGI Social subscale scores increased slightly with age, $r=.12, p=.04$. Additionally, female participants scored higher than male participants on the DGI-35 composite, $d=0.11, t(282)=4.09, p<.001$, and Physical, Social, and Achievement subscales (average $d=0.13$ ).

Measures. The DGI was administered again, and internal consistency remained adequate for the DGI-35 composite $(\alpha=$ .87 ) and subscale scores (average $\alpha=.73$ ). Demographic information was also collected, including age, race, and gender.

Self-control constructs. To provide additional evidence for convergent validity, the DGI was compared with three related measures. The 12-item Deferment of Gratification Questionnaire ( $\alpha=.71$; Ray \& Najman, 1986) assesses gratification delay with items such as "Do you fairly often find that it is worthwhile to wait and think things over before deciding?" The yes-no response format was altered to a scale from 1 (completely untrue) to 9 (completely true). Ego resiliency and impulse control were measured with Letzring, Block, and Funder's (2005) 14-item EgoResiliency Scale $(\alpha=.74)$ and 37-item Ego-Undercontrol Scale $(\alpha=.85)$. Items include "I usually think carefully about something before acting" and "I tend to buy things on impulse," rated on a scale from 1 (does not apply at all) to 4 (applies very strongly).

Food-related problems. Problematic eating behavior was measured with the 33-item Dutch Eating Behavior Questionnaire $(\alpha=.93$; van Strien, Frijters, Berger, \& Defares, 1986). Items like "Do you have a desire to eat when you are bored or restless?" are rated on a scale from 1 (never) to 5 (very often), and the scale produces three composite scores, including restrained eating, emo- tional eating, and external eating (eating when snacks are more readily available).

Physically risky behavior. Risky behaviors involving sex, drugs, and alcohol were measured with 30 items adapted from the Add Health Questionnaire ( $\alpha=.82$; Resnick et al., 1997), such as "Have you ever used chewing tobacco?" and "Have you ever paid someone for sex?"

Social problems. The 32-item Inventory of Interpersonal Problems-Short Circumplex form $(\alpha=.92$; Soldz, Budman, Demby, \& Merry, 1995) was used to measure social adjustment problems along eight dimensions: domineering, vindictive, cold, socially avoidant, nonassertive, exploitable, overly nurturant, and intrusive. Items like "I keep other people at a distance too much" were rated on a scale from 1 (completely disagree) to 5 (completely agree).

Money problems. Financial problems were assessed with 10 items adapted from the Add Health Questionnaire $(\alpha=.57$; Resnick et al., 1997), including "In the past 12 months, was there a time when you had to borrow money from a friend?" and "Do you have any credit card debt?"

Achievement problems. The 25-item Academic Maladjustment scale from the Student Adaptation to College Questionnaire $(\alpha=.86$; Baker \& Siryk, 1989) measured achievement problems with items like "I am attending classes regularly" rated from 1 (applies very closely to me) to 9 (doesn't apply to me at all).

Psychopathology. The 338-item MMPI-2-RF (Ben-Porath \& Tellegen, 2008) measures psychopathology along 50 overlapping dimensions with a true-false format. The MMPI-2-RF was administered in a group setting 2 weeks after the initial measures were completed online.

\section{Results and Discussion}

Scores on the DGI were related to those on a variety of other measures of self-control, adjustment, and psychopathology. As hypothesized, the DGI demonstrated continued evidence of construct validity by correlating well with self-control measures, and domains were related to adjustment problems in theoretically meaningful ways (see Table 6). The food domain was associated with binge eating and idle snacking (external eating). The physical domain was related to substance use and number of sexual partners. The social domain predicted a broad range of interpersonal problems, although several domains had relevant correlates. The money domain was mildly predictive of problematic personal financial behaviors as well as substance use. Further, the achievement domain was strongly related to academic adjustment.

DGI scores were also associated with scores on the MMPI-2-RF (see Table 7). In general, DGI scores were associated with scores indicating positive psychological adjustment, as noted by associations with validity indices and negative correlations with substantive scales. In particular, DGI scores were powerfully predictive of decreased externalizing symptoms, as measured by the MMPI-2-RF Behavioral/ Externalizing scale, Antisocial Behavior scale, Juvenile Conduct Problems scale, Substance Abuse scale, and related scales. Correlates varied across domains. Those scoring high on the food domain were less likely to have substance problems, atypical or unhelpful thinking patterns, hypomanic symptoms, and behavior problems. They were also more likely to be introverted. The physical domain was robustly related to fewer externalizing problems (e.g., $r=-.57$ with Juvenile 
Table 6

Correlations Between Scores on the Delaying Gratification Inventory (DGI), Self-Control Measures, and Adjustment Measures in Study 4

\begin{tabular}{|c|c|c|c|c|c|c|c|}
\hline Measure & Food & Physical & Social & Money & Achievement & DGI-10 & DGI-35 \\
\hline \multicolumn{8}{|l|}{ Self-control } \\
\hline DGQ & .36 & .47 & .31 & .73 & .39 & .58 & .67 \\
\hline Ego Undercontrol Scale & -.29 & -.44 & -.28 & -.38 & -.27 & -.40 & -.48 \\
\hline Ego Resiliency Scale & .12 & .10 & .27 & .01 & .28 & .27 & .21 \\
\hline \multicolumn{8}{|l|}{ Eating pathology (DEBQ) } \\
\hline Restrained eating & .10 & .05 & .13 & .04 & .07 & .12 & .11 \\
\hline Emotional eating & -.39 & -.09 & -.05 & -.17 & -.08 & -.19 & -.23 \\
\hline External eating & -.39 & -.30 & -.09 & -.19 & -.08 & -.20 & -.30 \\
\hline \multicolumn{8}{|c|}{ Physically risky behavior (AHQ) } \\
\hline Substance problems & -.18 & -.48 & -.13 & -.22 & -.15 & -.25 & -.33 \\
\hline Cigarette smoking & -.10 & -.26 & -.03 & -.14 & -.14 & -.23 & -.20 \\
\hline Alcohol use & -.15 & -.38 & -.14 & -.19 & -.19 & -.23 & -.30 \\
\hline Marijuana use & -.03 & -.27 & -.06 & -.16 & -.09 & -.15 & -.18 \\
\hline Risky sexual behavior & -.08 & -.16 & -.09 & -.15 & -.10 & -.12 & -.17 \\
\hline Frequency of sex & -.02 & -.14 & .03 & -.16 & -.01 & -.04 & -.09 \\
\hline No. of sexual partners & -.09 & -.32 & -.17 & -.14 & -.09 & -.14 & -.22 \\
\hline \multicolumn{8}{|l|}{ Social problems (IIPSC) } \\
\hline Domineering & -.31 & -.23 & -.26 & -.07 & -.13 & -.26 & -.28 \\
\hline Vindictive & -.27 & -.25 & -.29 & -.08 & -.19 & -.27 & -.30 \\
\hline Cold & -.17 & -.16 & -.24 & .04 & -.18 & -.24 & -.19 \\
\hline Socially avoidant & -.10 & -.10 & -.12 & .01 & -.20 & -.22 & -.14 \\
\hline Nonassertive & -.06 & -.06 & .11 & .05 & -.04 & -.02 & .00 \\
\hline Exploitable & -.07 & -.10 & .10 & -.06 & -.08 & -.10 & -.07 \\
\hline Overly nurturant & -.07 & .02 & .20 & -.03 & .00 & -.03 & .02 \\
\hline Intrusive & -.17 & -.26 & -.13 & -.16 & -.12 & -.17 & -.24 \\
\hline \multicolumn{8}{|l|}{ Monetary distress (AHQ) } \\
\hline Financial problems & -.07 & -.15 & -.04 & -.17 & -.03 & -.06 & -.14 \\
\hline Borrowed money & -.14 & -.16 & .00 & -.17 & -.10 & -.09 & -.17 \\
\hline Paid research subject & -.11 & -.17 & -.03 & -.25 & -.09 & -.14 & -.20 \\
\hline \multicolumn{8}{|c|}{ Achievement problems (SACQ) } \\
\hline Academic maladjustment & -.17 & -.34 & -.29 & -.25 & -.62 & -.48 & -.48 \\
\hline
\end{tabular}

Note. $n=284$. To facilitate visual inspection, statistically significant correlations are in bold $(p<.05)$. DGQ $=$ Deferment of Gratification Questionnaire $\mathrm{DEBQ}=$ Dutch Eating Behavior Questionnaire; AHQ = Add Health Questionnaire; IIPSC = Inventory of Interpersonal Problems-Short Circumplex; SACQ $=$ Student Adaptation to College Questionnaire.

Conduct Problems scale and $r=-.51$ with Behavioral/Externalizing scale scores), better self-control, fewer hypomanic symptoms, and less anger, aggression, and resentment. The social domain was solely related to externalizing behaviors, and the money domain was solely related to substance abuse. Finally, the achievement domain was associated with reduced symptoms of depression, increased activation, fewer juvenile conduct problems, and more cerebral interests. Results demonstrate the utility of the DGI in predicting adjustment issues and follow-up studies involving clinical samples are warranted.

\section{General Discussion}

The present investigation drew on 6 decades of research to shape the development of the first known theoretically driven five-factor measure of individual differences in the tendency to delay gratification, the DGI. The DGI was designed to provide practical and psychometric advantages over past methods of measurement (Mauro \& Harris, 2000; Nederkoorn et al., 2006; Smith \& Hantula, 2008), thereby accelerating social and behavioral public health research (DeWall et al., 2007; Gottdiener et al., 2008; National Institutes of Health, 2009; Seeyave et al., 2009). Our innovative Web-based strategy for survey development and validation bolstered the recruitment of over 10,000 adult participants worldwide, and participants were diverse in age, race, and educational attainment. Scores on the resulting scale showed strong internal consistency, test-retest reliability, factor structure, and construct validity. Further, findings have implications for clinical and public health strategies, follow-up studies, and test construction projects.

Consistent with the hypothesized multidimensionality of gratification delay, the study procedures produced a psychometrically strong survey measuring five domains of delay behavior, involving food, physical pleasures, social interactions, money, and achievement. Across studies and samples, scores on the DGI-35 composite, the DGI-10 short form, and the five domains met conventional standards for internal consistency and test-retest reliability. The full 35-item form clearly provides the richest set of information, but the reliability of the short-form composite supports its standalone use for studies in which a lengthier measure may be overly burdensome. Additionally, the theoretically derived five-factor model fit the data well and was relatively robust when examined across various subgroups, showing little measurement invariance when constrained by factor structure, factor loadings, or the factor variance-covariance matrix.

The four studies in the present investigation clearly demonstrate that DGI composite and domain scores correlate with theoretically 
Table 7

Correlations Between Scores on the Delaying Gratification Inventory (DGI) and MMPI-2-RF Psychopathology Scales in Study 4

\begin{tabular}{|c|c|c|c|c|c|c|c|}
\hline MMPI-2-RF & Food & Physical & Social & Money & Achievement & DGI-10 & DGI-35 \\
\hline \multicolumn{8}{|l|}{ Response validity scales } \\
\hline Variable Responding (VRIN-r) & -.05 & -.09 & -.05 & .17 & .12 & .05 & .03 \\
\hline True Response Inconsistency (TRIN-r) & -.14 & -.02 & -.26 & .08 & .12 & -.03 & -.05 \\
\hline Infrequent Responses (F-r) & -.03 & -.31 & -.07 & .02 & -.07 & -.14 & -.13 \\
\hline Infrequent Psychopathology Responses (Fp-r) & -.17 & -.25 & -.21 & .15 & -.07 & -.06 & -.15 \\
\hline Infrequent Somatic Responses (Fs) & .01 & -.02 & .07 & .09 & .09 & -.01 & .06 \\
\hline Symptom Validity (FBS-r) & .04 & .00 & .17 & .20 & .07 & .13 & .14 \\
\hline Uncommon Virtues (L-r) & .31 & .35 & .05 & .19 & .06 & .24 & .29 \\
\hline Defensiveness (K-r) & .30 & .19 & .06 & .03 & .14 & .17 & .21 \\
\hline \multicolumn{8}{|l|}{ Higher order scales } \\
\hline Emotional/Internalizing (EID) & -.01 & -.05 & .11 & .05 & -.12 & -.04 & -.01 \\
\hline Thought Dysfunction (THD) &.- .33 & -.18 & .13 & -.06 & .19 & -.08 & -.10 \\
\hline Behavioral/Externalizing (BXD) & -.19 & -.51 & -.31 & -.23 & -.20 & -.29 & -.41 \\
\hline \multicolumn{8}{|l|}{$\begin{array}{l}\text { Restructured clinical scales } \\
\text { RAD) }\end{array}$} \\
\hline Demoralization $(\mathrm{RCd})$ & -.13 & -.06 & .00 & .07 & -.14 & -.08 & -.07 \\
\hline Somatic Complaints ( $\mathrm{RC} 1)$ & -.02 & -.11 & -.06 & .14 & .01 & -.06 & -.01 \\
\hline Low Positive Emotions (RC2) & .11 & -.04 & .10 & .08 & -.31 & -.02 & -.01 \\
\hline Cynicism (RC3) & -.29 & -.26 & -.13 & -.14 & -.11 & -.17 & -.27 \\
\hline Antisocial Behavior (RC4) & -.31 & -.49 & -.36 & -.23 & -.09 & -.36 & -.42 \\
\hline Ideas of Persecutions (RC6) &.- .35 & -.36 & -.05 & -.01 & .02 & -.20 & -.23 \\
\hline Dysfunctional Negative Emotions (RC7) & -.28 & -.08 & .00 & .07 & .14 & -.08 & -.05 \\
\hline Aberrant Experiences (RC8) &.- .30 & -.22 & .09 & -.10 & .06 & -.12 & -.15 \\
\hline Hypomanic Activation (RC9) &.- .35 & -.36 & -.19 & -.12 & -.01 & -.20 & -.30 \\
\hline \multicolumn{8}{|l|}{ Personality psychopathology five } \\
\hline Aggressiveness (AGGR-r) & -.14 & -.21 & -.14 & -.13 & .07 & -.11 & -.16 \\
\hline Psychoticism (PSYC-r) & -.22 & -.13 & .09 & -.03 & .07 & -.04 & -.08 \\
\hline Disconstraint (DISC-r) & -.12 & -.46 & -.23 & -.21 & -.17 & -.26 & -.34 \\
\hline Negative Emotionality (NEGE-r) & -.16 & -.09 & .05 & -.02 & .18 & -.05 & -.03 \\
\hline Introversion (INTR-r) & .28 & .10 & -.03 & .09 & -.24 & .05 & .08 \\
\hline \multicolumn{8}{|l|}{ Somatic } \\
\hline Malaise (MLS) & -.01 & -.03 & .17 & .20 & -.04 & .13 & .08 \\
\hline Gastro-Intestinal Complaints (GIC) & -.05 & -.12 & .00 & .11 & -.07 & -.04 & -.03 \\
\hline Head Pain Complaints (HPC) & .05 & -.13 & .13 & .01 & .02 & .02 & .02 \\
\hline Neurological Complaints (NUC) & -.20 & -.26 & -.23 & .02 & -.07 & -.16 & -.20 \\
\hline Cognitive Complaints (COG) & -.11 & -.17 & .05 & .05 & -.05 & -.08 & -.07 \\
\hline \multicolumn{8}{|l|}{ Internalizing } \\
\hline Suicidal/Death Ideation (SUI) & -.14 & -.10 & -.02 & .14 & .01 & .03 & -.03 \\
\hline Helplessness/Hopelessness (HLP) & -.11 & -.23 & .02 & .05 & -.27 & -.12 & -.15 \\
\hline Self-Doubt (SFD) & -.08 & .06 & .09 & .06 & -.08 & -.06 & .02 \\
\hline Inefficacy (NFC) & -.23 & -.09 & -.05 & -.10 & -.13 & -.17 & -.17 \\
\hline Stress/Worry (STW) & -.09 & -.04 & .08 & -.07 & .06 & .00 & -.03 \\
\hline Anxiety (AXY) & .02 & -.07 & .24 & .23 & .10 & .08 & .14 \\
\hline Anger Proneness (ANP) & -.22 & -.30 & -.19 & -.07 & -.07 & -.23 & -.24 \\
\hline Behavior-Restricting Fears (BRF) & -.02 & .07 & .08 & .15 & .12 & .04 & .11 \\
\hline Multiple Specific Fears (MSF) & -.23 & -.13 & .13 & -.08 & -.02 & .03 & -.11 \\
\hline \multicolumn{8}{|l|}{ Externalizing } \\
\hline Juvenile Conduct Problems (JCP) & -.27 & -.57 & -.40 & -.18 & -.33 & -.36 & -.49 \\
\hline Substance Abuse (SUB) & -.37 & -.49 & -.26 & -.30 & .06 &.- .33 & -.40 \\
\hline Aggression (AGG) & -.17 & -.31 & -.14 & -.14 & -.07 & -.18 & -.24 \\
\hline Activation (ACT) & -.35 & .03 & .19 & .01 & .35 & .05 & .04 \\
\hline \multicolumn{8}{|l|}{ Interpersonal scales } \\
\hline Family Problems (FML) & -.09 & .10 & .10 & .14 & .18 & .03 & .12 \\
\hline Interpersonal Passivity (IPP) & .11 & .10 & .04 & .12 & -.20 & -.04 & .06 \\
\hline Social Avoidance (SAV) & .14 & .13 & -.09 & .12 & -.13 & .04 & .07 \\
\hline Shyness (SHY) & -.09 & -.07 & -.16 & -.10 & -.17 & -.17 & -.16 \\
\hline Disaffiliativeness (DSF) & .21 & .10 & -.15 & .08 & -.14 & -.05 & .05 \\
\hline \multicolumn{8}{|l|}{ Interest scales } \\
\hline Aesthetic-Literary Interests (AES) & -.16 & .01 & .10 & .16 & .28 & .15 & .10 \\
\hline Mechanical-Physical Interests (MEC) & .22 & -.18 & -.12 & -.05 & -.23 & -.10 & -.09 \\
\hline
\end{tabular}

Note. $n=56$. Parenthetical acronyms refer to official MMPI-2-RF scale names. To facilitate visual inspection, statistically significant correlations are in bold $(p<.05)$. MMPI-2-RF = Minnesota Multiphasic Personality Inventory-2-Restructured Form.

relevant traits, behavioral tendencies, adjustment problems, and psychopathology symptoms. People who generally delay gratification well, as indicated by the DGI-35 composite score, also scored highly on other measures of self-control, conscientiousness, self-discipline, and achievement striving, supporting the basic construct validity of the measure. Additionally, delaying gratification was modestly associated with improved health and well-being, increased exercise, better diet, altruistic and agreeable traits, and openness to experience. Those scoring high on delay of gratification also have somewhat reduced levels of binge eating, neuroticism, depression, anxiety, anger, rebelliousness, sensation seeking, substance use, risky sexual behavior, interpersonal problems, externalizing problems, and hypomanic symptoms. These results corroborate and extend prior findings relating gratification delay to 
improved psychosocial adjustment (Bembenutty \& Karabenick, 2004; Funder \& Block, 1989; Mischel \& Mischel, 1983; Funder et al., 1983; Lee et al., 2008; Ramanathan \& William, 2007). The general pattern of correlations was similar, although slightly attenuated, for scores on the DGI-10 short-form composite scale, indicating its utility when administration of a lengthier scale might be untenable. Additionally, correlates of DGI domain scores were distinct and varied in theoretically meaningful ways. The food domain was related to dietary habits, preoccupation with food, and activity level. The physical domain was the greatest predictor of externalizing behaviors, including aggression, sensation seeking, substance use, risky sexual behavior, and rule breaking. The social domain was related to altruism, interpersonal warmth, openmindedness, and prosocial behavior. The money domain was related to splurging, paying bills on time, and financial distress. Finally, the academic domain was related to conscientiousness, achievement striving, academic adjustment, and well-being.

The present investigation must be qualified by several important limitations. First, findings were based primarily on a broad, diverse sample of general adults, and no claims are made about the generalizability of DGI correlates to specialized or clinical populations. Studies linking gratification delay to specific physical and mental health problems are encouraged, particularly given that findings involving the MMPI-2-RF were restricted to an undergraduate sample. Second, outcome measures relied on self-report. The incorporation of structured behavioral observations, medical record data, or other methods that do not rely on self-report would provide additional tests of validity. Third, although test-retest correlations provide evidence for the stability of DGI scores, this investigation does not directly address the degree to which gratification delay is modifiable, indicating that prospective intervention studies on emotional skill development are warranted. Fourth, additional evidence documenting the association between DGI money scores and significant real-world financial behavior is needed. Potential avenues include predicting business success, bankruptcy, credit card debt, and retirement planning.

Study limitations are balanced by several strengths worth noting. First, the use of large, diverse worldwide samples in Studies 1 and 2 afforded substantial statistical power and facilitated the generalizability of the resulting scale. Second, the technico-ethical rigor of the study website reinforced American Psychological Association ethical guidelines for Internet-mediated research (Hoerger \& Currell, in press), facilitated participant recruitment and enjoyment, and suggests strategies for future Web-based researchers. Third, the DGI was designed for flexible and widespread use. The measure is nonproprietary, and clinicians and researchers have the option of administering the 35-item inventory or the 10-item short form, depending on their constraints and interests.

In conclusion, we hope the development of the DGI will provide a significant step forward in research on gratification delay. Scores on the DGI have strong psychometric properties and can be administered efficiently to diverse samples of adults. Regarding the investigation's clinical and public health implications, the DGI could be used by trained individual therapists, Department of Social Services workers, school counselors, community social workers, prison group therapists, Alcoholics Anonymous, occupational rehabilitation programs, and pastoral counselors to identify individuals at risk for particular adjustment problems and to better route clients to appropriate intervention services. The scale can also be incorporated into public health studies attempting to predict academic achievement, externalizing behavior problems, psychopathology, consumer financial planning, and health care decision making. Finally, the methodological approach suggests avenues for efficient, low-cost survey development.

\section{References}

Baker, R., \& Siryk, B. (1989). SACQ: Student Adaptation to College Questionnaire manual. Los Angeles, CA: Western Psychological Services.

Baumeister, R. F., Heatherton, T. F., \& Tice, D. M. (1994). Losing control: How and why people fail at self-regulation. San Diego, CA: Academic Press.

Baumeister, R. F., \& Vohs, K. D. (2004). Understanding self-regulation: An introduction. In R. F. Baumeister (Ed.), Handbook of self-regulation: Research, theory, and applications (p. 2). New York, NY: Guilford Press.

Baumeister, R. F., Vohs, K., \& Tice, D. (2007). The strength model of self-control. Current Directions in Psychological Science, 16, 351-355. doi:10.1111/j.1467-8721.2007.00534.x

Bembenutty, H., \& Karabenick, S. (1998). Academic delay of gratification. Learning and Individual Differences, 10, 329-346. doi:10.1016/S10416080(99)80126-5

Bembenutty, H., \& Karabenick, S. (2004). Inherent association between academic delay of gratification, future time perspective, and selfregulated learning. Educational Psychology Review, 16, 35-57. doi: 10.1023/B:EDPR.0000012344.34008.5c

Ben-Porath, Y. S., \& Tellegen, A. (2008). The Minnesota Multiphasic Personality Inventory-2-Restructured Form: Manual for administration, scoring, and interpretation. Minneapolis, MN: University of Minnesota Press.

De Beuckelaer, A., \& Lievens, F. (2009). Measurement equivalence of paper-and-pencil and Internet organizational surveys: A large scale examination in 16 countries. Applied Psychology: An International Review, 58, 336-361. doi:10.1111/j.1464-0597.2008.00350.x

DeWall, C. N., Baumeister, R. F., Stillman, T. F., \& Galliot, M. T. (2007). Violence restrained: Effects of self-regulation and its depletion on aggression. Journal of Experimental Social Psychology, 43, 62-76. doi: 10.1016/j.jesp.2005.12.005

Donnellan, M. B., Oswald, F. L., Baird, B. M., \& Lucas, R. E. (2006). The Mini-IPIP Scales: Tiny-yet-effective measures of the Big Five factors of personality. Psychological Assessment, 18, 192-203. doi:10.1037/10403590.18.2.192

Funder, D., \& Block, J. (1989). The role of ego-control, ego-resiliency, and IQ in delay of gratification in adolescence. Journal of Personality and Social Psychology, 57, 1041-1050. doi:10.1037/0022-3514.57.6.1041

Funder, D., Block, J., \& Block, J. (1983). Delay of gratification: Some longitudinal personality correlates. Journal of Personality and Social Psychology, 44, 1198-1213. doi:10.1037/0022-3514.44.6.1198

Gailliot, M. T., Baumeister, R., DeWall, C., Maner, J., Plant, E., Tice, D., ... Schmeichel, B. (2007). Self-control relies on glucose as a limited energy source: Willpower is more than a metaphor. Journal of Personality and Social Psychology, 92, 325-336. doi:10.1037/00223514.92.2.325

Goldberg, L. R., Johnson, J. A., Eber, H. W., Hogan, R., Ashton, M. C., Cloninger, C. R., \& Gough, H. C. (2006). The International Personality Item Pool and the future of public-domain personality measures. Journal of Research in Personality, 40, 84-96. doi:10.1016/j.jrp.2005.08.007

Gosling, S. D., Vazire, S., Srivastava, S., \& John, O. (2004). Should we trust Web-based studies? A comparative analysis of six preconceptions about Internet questionnaires. American Psychologist, 59, 93-104. doi: 10.1037/0003-066X.59.2.93

Gottdiener, W., Murawski, P., \& Kucharski, L. (2008). Using the delay 
discounting task to test for failures in ego control in substance abusers: A meta-analysis. Psychoanalytic Psychology, 25, 533-549. doi:10.1037/ 0736-9735.25.3.533

Graham, J. (2006). MMPI-2: Assessing personality and psychopathology. New York, NY: Oxford University Press.

Hoerger, M. (2010). Participant dropout as a function of survey length in Internet-mediated university studies: Implications for study design and voluntary participation in psychological research. Cyberpsychology, Behavior, and Social Networking, 13, 697-700. doi:10.1089/ cyber.2009.0445

Hoerger, M., \& Currell, C. (in press). Ethical issues in Internet research. In: S. Knapp, L. VandeCreek, M. Handelsman, \& M. Gottlieb, (Eds), APA handbook of ethics in psychology. Washington, DC: American Psychological Association.

Kraut, R., Olson, J., Banaji, M., Bruckman, A., Cohen, J., \& Couper, M. (2004). Psychological research online: Report of Board of Scientific Affairs' Advisory Group on the conduct of research on the Internet. American Psychologist, 59, 105-117. doi:10.1037/0003-066X.59.2.105

Krug, S. (2005). Don't make me think: A common sense approach to Web usability (2nd ed.). Berkeley, CA: New Riders.

Lee, P., Lan, W., Wang, C., \& Chiu, H. (2008). Helping young children to delay gratification. Early Childhood Education Journal, 35, 557-564. doi:10.1007/s10643-008-0240-9

Letzring, T. D., Block, J., \& Funder, D. C. (2005). Ego-control and ego-resiliency: Generalization of self-report scales based on personality descriptions from acquaintances, clinicians, and the self. Journal of Research in Personality, 39, 395-422. doi:10.1016/j.jrp.2004.06.003

Mauro, C. F., \& Harris, Y. (2000). The influence of maternal child-rearing attitudes and teaching behaviors on preschoolers' delay of gratification. Journal of Genetic Psychology: Research and Theory on Human Development, 161, 292-306. doi:10.1080/00221320009596712

McLeish, K. N., \& Oxoby, R. J. (2007). Measuring impatience: Elicited discount rates and the Barratt Impulsiveness Scale. Personality and Individual Differences, 43, 553-565. doi:10.1016/j.paid.2007.01.002

Mischel, W. (1958). Preference for delayed reinforcement: An experimental study of a cultural observation. Journal of Abnormal and Social Psychology, 56, 57-61. doi:10.1037/h0041895

Mischel, W. (1996). From good intentions to willpower. In P. M. Gollwitzer \& J. A. Bargh (Eds.), The psychology of action: Linking cognitions and motivation to behavior (pp. 197-218). New York, NY: Guilford.

Mischel, W., \& Ayduk, O. (2002). Self-regulation in a cognitive-affective personality system: Attentional control in the service of the self. Self and Identity, 1, 113-120. doi:10.1080/152988602317319285

Mischel, W., Cantor, N., \& Feldman, S. (1996). Principles in selfregulation: The nature of willpower and self-control. In F. T. Higgins \& A. Gruglanski (Eds.), Social psychology: Handbook of basic principles (pp. 687-696). New York, NY: Guilford Press.

Mischel, W., \& Gilligan, C. (1964). Delay of gratification, motivation for the prohibited gratification, and responses to temptation. Journal of Abnormal and Social Psychology, 69, 411-417. doi:10.1037/h0048918

Mischel, H., \& Mischel, W. (1983). The development of children's knowledge of self-control strategies. Child Development, 54, 603-619.

Mischel, W., Shoda, Y., \& Peake, P. (1988). The nature of adolescent competencies predicted by preschool delay of gratification. Journal of Personality and Social Psychology, 54, 687-696.

Muraven, M., Baumeister, R., \& Tice, D. (1999). Longitudinal improvement of self-regulation through practice: Building self-control strength through repeated exercise. Journal of Social Psychology, 139, 446-457. doi:10.1080/00224549909598404

National Institutes of Health. (2009). NIH science of behavior change. Retrieved from http://nihroadmap.nih.gov/documents/SOBC_Meeting Summary_2009.pdf

Nederkoorn, C., Smulders, F., Havermans, R., Roefs, A., \& Jansen, A.
(2006). Impulsivity in obese women. Appetite, 47, 253-256. doi 10.1016/j.appet.2006.05.008

Nosek, B., Banaji, M., \& Greenwald, A. (2002). Harvesting implicit group attitudes and beliefs from a demonstration web site. Group Dynamics: Theory, Research, and Practice, 6, 101-115. doi:10.1037/10892699.6.1.101

Patton, J. H., Stanford, M. S., \& Barratt, E. S. (1995). Factor structure of the Barratt Impulsiveness Scale. Journal of Clinical Psychology, 51, 768-774. doi:10.1002/1097-4679(199511)51:6<768::AIDJCLP2270510607>3.0.CO;2-1

Ramanathan, S., \& Menon, G. (2006). Time-varying effects of chronic hedonic goals on impulsive behavior. Journal of Marketing Research, 43, 628-641. doi:10.1509/jmkr.43.4.628

Ramanathan, S., \& Williams, P. (2007). Immediate and delayed emotional consequences of indulgence: The moderating influence of personality type on mixed emotions. Journal of Consumer Research, 34, 212-223. doi: $10.1086 / 519149$

Rapaport, D. (1951). Organization and pathology of thought. New York, NY: Columbia University Press. doi:10.1037/10584-000

Ray, J., \& Najman, J. (1986). The generalizability of deferment of gratification. Journal of Social Psychology, 126, 117-119. doi:10.1080/ 00224545.1986.9713578

Resnick, M. D., Bearman, P. S., Blum, R. W., Bauman, K. E., Harris, K. M., Jones, J., ... Udry, J. R. (1997). Protecting adolescents from harm: Findings from the National Longitudinal Study on Adolescent Health. JAMA, 278, 823-832. doi:10.1001/jama.278.10.823

Reynolds, B. (2006). A review of delay-discounting research with humans: Relations to drug use and gambling. Behavioural Pharmacology, 17, 651-667. doi:10.1097/FBP.0b013e3280115f99

Richards, J. B., Zhang, L., Mitchell, S. H., \& de Wit, H. (1999). Delay or probability discounting in a model of impulsive behavior: Effect of alcohol. Journal of the Experimental Analysis of Behavior, 71, 121-143. doi:10.1901/jeab.1999.71-121

Satorra, A., \& Bentler, P. M. (1988). Scaling corrections for chi-square statistics in covariance structure analysis. In Proceedings of the Business and Economic Statistics Section of the American Statistical Association (pp. 308-313). Alexandria, VA: American Statistical Association.

Seeyave, D. M., Coleman, S., Appugliese, D., Corwyn, R. F., Bradley, R. H., Davidson, N. S., ... Lumeng, J. C. (2009). Ability to delay gratification at age 4 years and risk of overweight at age 11 years. Archives of Pediatrics and Adolescent Medicine, 163, 303-308.

Shamosh, N. A., DeYoung, C. G., Green, A. E., Reis, D. L., Johnson, M Conway, A. R. A., .. . Gray, J. (2008). Individual differences in delay discounting. Psychological Science, 19, 904-911. doi:10.1111/j.14679280.2008.02175.x

Singer, J. L., Meltzoff, J., \& Goldman, G. D. (1952). Rorschach movement responses following motor inhibition and hyperactivity. Journal of Consulting Psychology, 16, 359-364. doi:10.1037/h0063452

Smith, C. L., \& Hantula, D. A. (2008). Methodological considerations in the study of delay discounting in intertemporal choice: A comparison of tasks and modes. Behavior Research Methods, 40, 940-953. doi: 10.3758/BRM.40.4.940

Soldz, S., Budman, S., Demby, A., \& Merry, J. (1995). A Short Form of the Inventory of Interpersonal Problems Circumplex Scales. Assessment, 2 53-63. doi:10.1177/1073191195002001006

Srivastava, S., John, O. P., Gosling, S. D., \& Potter, J. (2003). Development of personality in adulthood: Set like plaster or persistent change? Journal of Personality and Social Psychology, 84, 1041-1053. doi: 10.1037/0022-3514.84.5.1041

Tangney, J. P., Baumeister, R. F., \& Boone, A. L. (2004). High self-control predicts good adjustment, less pathology, better grades, and interpersonal success. Journal of Personality, 72, 271-322.

Twenge, J. M., Catanese, K. R., \& Baumeister, R. F. (2003). Social exclusion and the deconstructed state: Time perception, meaningless- 
ness, lethargy, lack of emotion, and self-awareness. Journal of Personality and Social Psychology, 85, 409-423. doi:10.1037/00223514.85.3.409

van Strien, T., Frijters, J. E. R., Berger, G. P. A., \& Defares, P. B. (1986). The Dutch Eating Behavior Questionnaire (DEBQ) for assessment of restrained, emotional, and external eating behavior. International Journal of Eating Disorders, 5, 295-315. doi:10.1002/1098-108X(198602)5:2<295::AIDEAT2260050209>3.0.CO;2-T

Wanous, J. P., Reichers, A. E., \& Hudy, M. J. (1997). Overall job satisfaction: How good are single-item measures? Journal of Applied Psychology, 82, 247-252. doi:10.1037/0021-9010.82.2.247

Ward, W. E., Perry, T. B., Woltz, J., \& Doolin, E. (1989). Delay of gratification among Black college student leaders. Journal of Black Psychology, 15, 111-128. doi:10.1177/00957984890152004
Wormith, J., \& Hasenpusch, B. (1979). Multidimensional measurement of delayed gratification preference with incarcerated offenders. Journal of Clinical Psychology, 35, 218-225.

Wulfert, E., Safren, S., Brown, I., \& Wan, C. (1999). Cognitive, behavioral, and personality correlates of HIV-positive persons' unsafe sexual behavior. Journal of Applied Social Psychology, 29, 223-244. doi: 10.1111/j.1559-1816.1999.tb01383.x

Received October 5, 2010 Revision received December 22, 2010 Accepted January 24, 2011 


\section{Appendix A}

Online Supplemental Materials: Figures

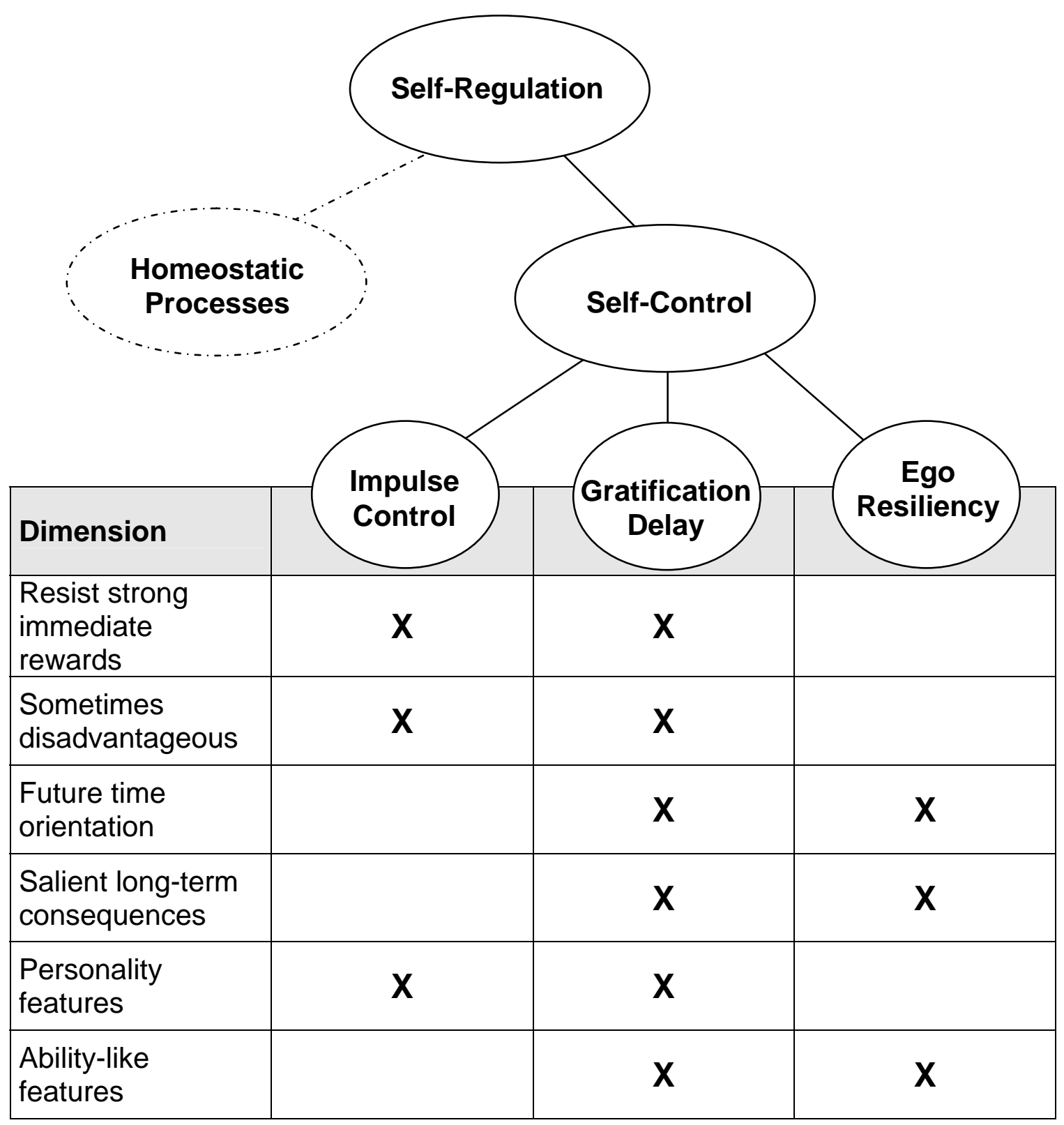

Figure A1. Hierarchy of self-regulation and related constructs. 
Appendix A (continued)

Online Supplemental Materials: Figures

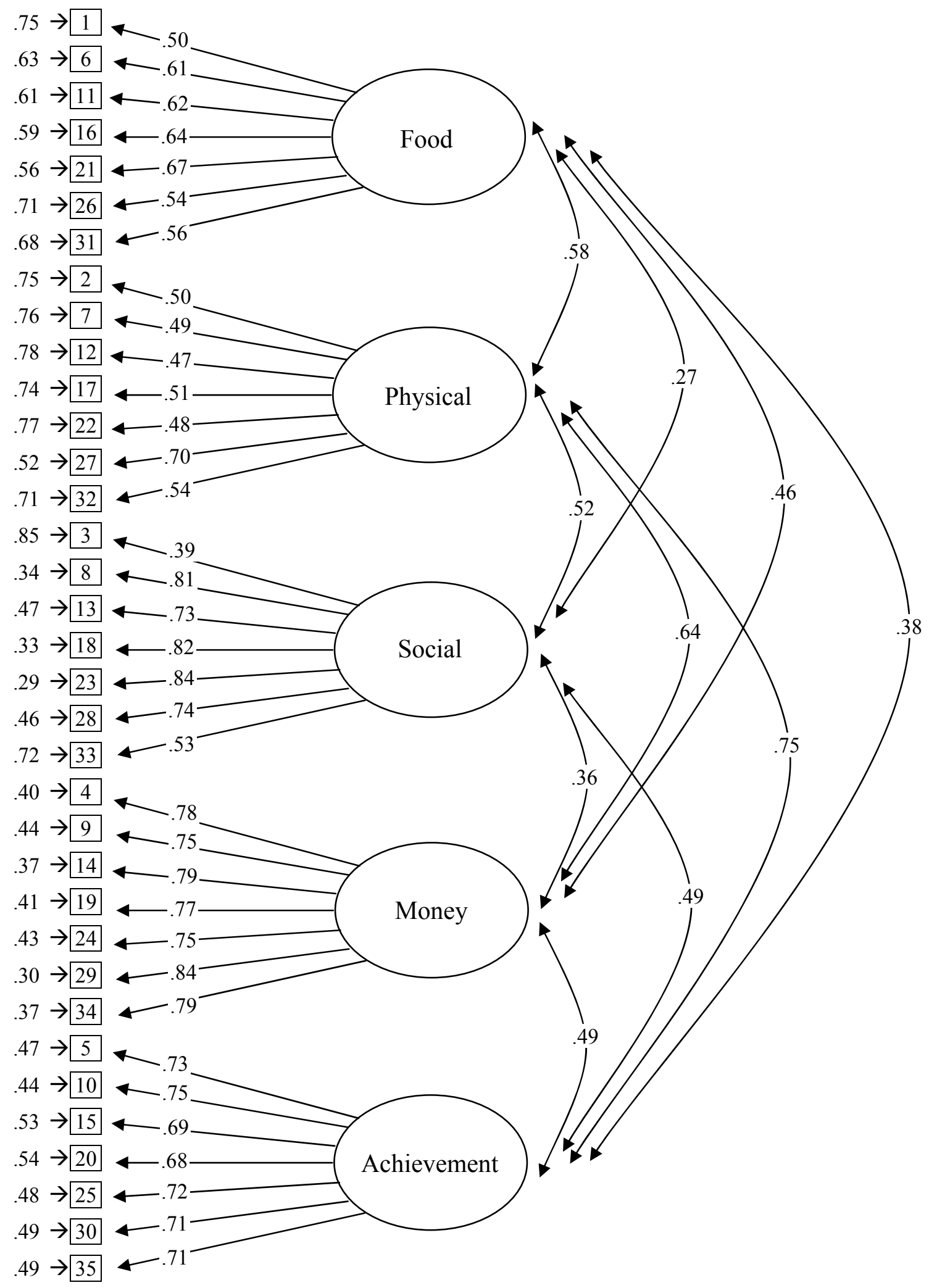

Figure A2. Confirmatory factor analysis for entire worldwide sample. 


\section{Appendix B}

Online Supplemental Materials: Tables

Table B1

Summary of Research Articles Describing Overlap of Five Factors

\begin{tabular}{|c|c|c|c|c|c|c|}
\hline Year & Author(s) & Food & Physical & Social & Money & Achievement \\
\hline 2008 & Lee et al. & & & $\mathrm{X}$ & & $\mathrm{X}$ \\
\hline 2007 & Baumeister et al. & $\mathrm{X}$ & $\mathrm{X}$ & $\mathrm{X}$ & $\mathrm{X}$ & $\mathrm{X}$ \\
\hline 2007 & Ramanathan \& Williams & $\mathrm{X}$ & $\mathrm{X}$ & & $\mathrm{X}$ & \\
\hline 2006 & Nederkoorn et al. & $\mathrm{X}$ & $\mathrm{X}$ & & & \\
\hline 2006 & Ramanathan \& Menon & $\mathrm{X}$ & $\mathrm{X}$ & & $\mathrm{X}$ & \\
\hline 2004 & Bembenutty \& Karabenick & $\mathrm{X}$ & & $\mathrm{X}$ & & $\mathrm{X}$ \\
\hline 2003 & Marcus & & $\mathrm{X}$ & $\mathrm{X}$ & & \\
\hline 1998 & Bembenutty \& Karabenick & & $\mathrm{X}$ & $\mathrm{X}$ & & $\mathrm{X}$ \\
\hline 1994 & Baumeister et al. & $\mathrm{X}$ & $\mathrm{X}$ & & $\mathrm{X}$ & \\
\hline 1988 & Mischel et al. & $\mathrm{X}$ & & $\mathrm{X}$ & & $\mathrm{X}$ \\
\hline 1978 & Poggie & & & & $\mathrm{X}$ & $\mathrm{X}$ \\
\hline 1966 & Phillips & & $\mathrm{X}$ & $\mathrm{X}$ & $\mathrm{X}$ & $\mathrm{X}$ \\
\hline 1955 & Singer & $\mathrm{X}$ & $\mathrm{X}$ & $\mathrm{X}$ & & \\
\hline
\end{tabular}

Note. Food $=$ delay involving food, Phys $=$ physical delay, Social $=$ delay for social rewards, Money $=$ monetary delay, Ach $=$ delay for achievement 


\section{Appendix B (continued)}

Table B2

Online Supplemental Materials: Tables

Item Properties in Study 1

\begin{tabular}{|c|c|c|c|c|c|c|c|c|}
\hline Item & $M$ & $S D$ & Food & Phys & Soc & Money & Ach & Total \\
\hline \multicolumn{9}{|c|}{ Food } \\
\hline 16 & 3.27 & 1.32 & .59 & .23 & .09 & .21 & .12 & .34 \\
\hline 21 & 3.64 & 1.26 & .53 & .26 & .12 & .24 & .17 & .37 \\
\hline 6 & 2.89 & 1.31 & .49 & .31 & .16 & .29 & .27 & .43 \\
\hline 11 & 2.69 & 1.29 & .48 & .31 & .18 & .28 & .20 & .40 \\
\hline 31 & 3.27 & 1.26 & .47 & .25 & .16 & .21 & .14 & .34 \\
\hline 1 & 3.84 & 1.34 & .42 & .28 & .17 & .25 & .21 & .38 \\
\hline 26 & 3.11 & 1.17 & .39 & .26 & .17 & .27 & .29 & .40 \\
\hline \multicolumn{9}{|c|}{ Physical } \\
\hline 27 & 2.98 & 1.32 & .30 & .49 & .25 & .39 & .48 & .54 \\
\hline 22 & 3.55 & 1.31 & .15 & .47 & .26 & .22 & .28 & .38 \\
\hline 12 & 3.99 & 1.21 & .17 & .45 & .22 & .25 & .28 & .38 \\
\hline 2 & 3.41 & 1.13 & .32 & .38 & .18 & .23 & .28 & .40 \\
\hline 7 & 3.13 & 1.21 & .32 & .37 & .19 & .27 & .33 & .42 \\
\hline 32 & 2.57 & 1.19 & .25 & .36 & .18 & .24 & .37 & .40 \\
\hline 17 & 3.39 & 1.19 & .25 & .29 & .25 & .21 & .36 & .42 \\
\hline \multicolumn{9}{|c|}{ Social } \\
\hline 23 & 4.09 & 1.07 & .20 & .32 & .64 & .25 & .32 & .45 \\
\hline 8 & 4.16 & 0.97 & .18 & .28 & .64 & .19 & .27 & .40 \\
\hline 18 & 3.99 & 1.01 & .18 & .31 & .64 & .19 & .32 & .43 \\
\hline 28 & 4.07 & 0.86 & .14 & .25 & .62 & .13 & .28 & .36 \\
\hline 13 & 4.44 & 0.85 & .11 & .22 & .55 & .16 & .23 & .33 \\
\hline 33 & 4.55 & 0.71 & .09 & .13 & .43 & .06 & .18 & .23 \\
\hline 3 & 3.48 & 1.16 & .17 & .24 & .32 & .16 & .18 & .29 \\
\hline \multicolumn{9}{|c|}{ Money } \\
\hline 29 & 3.36 & 1.19 & .28 & .35 & .14 & .71 & .32 & .51 \\
\hline 34 & 3.63 & 1.21 & .30 & .31 & .17 & .71 & .23 & .48 \\
\hline 4 & 3.64 & 1.16 & .33 & .33 & .19 & .70 & .26 & .51 \\
\hline 14 & 3.99 & 0.95 & .30 & .34 & .23 & .66 & .32 & .53 \\
\hline 9 & 3.76 & 1.28 & .30 & .33 & .16 & .61 & .21 & .46 \\
\hline 24 & 3.77 & 1.22 & .24 & .31 & .19 & .61 & .31 & .47 \\
\hline 19 & 4.30 & 1.04 & .31 & .36 & .24 & .61 & .34 & .53 \\
\hline \multicolumn{9}{|c|}{ Achievement } \\
\hline 10 & 3.87 & 1.16 & .15 & .37 & .25 & .23 & .66 & .46 \\
\hline 5 & 3.61 & 1.24 & .17 & .37 & .28 & .23 & .63 & .46 \\
\hline 30 & 3.76 & 1.14 & .21 & .42 & .26 & .26 & .59 & .49 \\
\hline 25 & 3.32 & 1.37 & .29 & .50 & .26 & .31 & .59 & .55 \\
\hline 35 & 4.19 & 0.98 & .20 & .41 & .26 & .23 & .56 & .47 \\
\hline 15 & 3.13 & 1.37 & .23 & .46 & .25 & .30 & .56 & .50 \\
\hline 20 & 3.72 & 1.18 & .27 & .45 & .30 & .28 & .55 & .52 \\
\hline
\end{tabular}

Note. $n=1,900$. Values for the Food, Physical, Social, Money, Achievement, and Total columns refer to item-total and corrected item-total correlations. To facilitate visual inspection, correlations greater than magnitude $r=.35$ are in bold. Items are presented in order of descending corrected item-total correlations by subscale. 


\section{Appendix B (continued)}

Table B3

Online Supplemental Materials: Tables

Item Properties in Study 2

\begin{tabular}{|c|c|c|c|c|c|c|c|c|}
\hline Item & $M$ & $S D$ & Food & Phys & Soc & Money & Ach & Total \\
\hline \multicolumn{9}{|l|}{ Food } \\
\hline 16 & 3.08 & 1.32 & .50 & .20 & .09 & .17 & .14 & .30 \\
\hline 21 & 3.93 & 1.13 & .51 & .25 & .15 & .23 & .18 & .36 \\
\hline 6 & 2.79 & 1.30 & .48 & .29 & .13 & .25 & .22 & .38 \\
\hline 11 & 2.61 & 1.25 & .48 & .30 & .16 & .28 & .16 & .38 \\
\hline 31 & 3.36 & 1.26 & .44 & .26 & .17 & .21 & .19 & .35 \\
\hline 1 & 3.47 & 1.41 & .38 & .26 & .12 & .20 & .16 & .31 \\
\hline 26 & 3.27 & 1.21 & .42 & .33 & .21 & .31 & .34 & .45 \\
\hline \multicolumn{9}{|c|}{ Physical } \\
\hline 27 & 3.02 & 1.31 & .36 & .49 & .29 & .43 & .47 & .57 \\
\hline 22 & 3.45 & 1.27 & .11 & .46 & .25 & .26 & .25 & .35 \\
\hline 12 & 3.96 & 1.19 & .12 & .42 & .28 & .24 & .26 & .35 \\
\hline 2 & 3.44 & 1.14 & .30 & .38 & .21 & .27 & .29 & .41 \\
\hline 7 & 2.99 & 1.24 & .36 & .31 & .20 & .26 & .35 & .42 \\
\hline 32 & 2.34 & 1.21 & .23 & .40 & .24 & .30 & .31 & .41 \\
\hline 17 & 3.18 & 1.25 & .29 & .35 & .26 & .30 & .30 & .45 \\
\hline \multicolumn{9}{|c|}{ Social } \\
\hline 23 & 4.28 & 0.92 & .17 & .34 & .67 & .28 & .33 & .46 \\
\hline 8 & 4.16 & 0.93 & .15 & .29 & .66 & .23 & .29 & .41 \\
\hline 18 & 3.98 & 0.99 & .20 & .37 & .66 & .28 & .38 & .49 \\
\hline 28 & 4.17 & 0.82 & .16 & .30 & .61 & .20 & .32 & .41 \\
\hline 13 & 4.54 & 0.80 & .12 & .26 & .56 & .24 & .25 & .37 \\
\hline 33 & 4.56 & 0.68 & .10 & .15 & .42 & .14 & .21 & .26 \\
\hline 3 & 3.59 & 1.14 & .20 & .27 & .33 & .22 & .20 & .33 \\
\hline \multicolumn{9}{|c|}{ Money } \\
\hline 29 & 3.54 & 1.16 & .31 & .44 & .25 & .74 & .41 & .60 \\
\hline 34 & 3.60 & 1.22 & .31 & .40 & .23 & .71 & .28 & .54 \\
\hline 4 & 3.68 & 1.26 & .29 & .36 & .23 & .70 & .26 & .51 \\
\hline 14 & 4.08 & 0.98 & .28 & .40 & .32 & .67 & .38 & .57 \\
\hline 9 & 3.91 & 1.25 & .30 & .37 & .24 & .65 & .26 & .51 \\
\hline 24 & 3.96 & 1.19 & .26 & .36 & .27 & .65 & .36 & .53 \\
\hline 19 & 4.35 & 1.01 & .27 & .37 & .29 & .62 & .34 & .53 \\
\hline \multicolumn{9}{|c|}{ Achievement } \\
\hline 10 & 3.90 & 1.17 & .15 & .34 & .27 & .28 & .65 & .46 \\
\hline 5 & 3.53 & 1.27 & .15 & .36 & .28 & .26 & .64 & .46 \\
\hline 30 & 3.92 & 1.06 & .24 & .39 & .31 & .33 & .59 & .52 \\
\hline 25 & 3.39 & 1.38 & .34 & .50 & .31 & .36 & .59 & .58 \\
\hline 35 & 4.27 & 0.92 & .24 & .37 & .32 & .25 & .58 & .48 \\
\hline 15 & 3.27 & 1.34 & .23 & .45 & .29 & .31 & .59 & .52 \\
\hline 20 & 3.77 & 1.17 & .24 & .39 & .31 & .30 & .57 & .50 \\
\hline
\end{tabular}

Note. $n=7,771$. Values for the Food, Physical, Social, Money, Achievement, and Total columns refer to item-total and corrected item-total correlations. To facilitate visual inspection, correlations greater than magnitude $r=.35$ are in bold. Items are presented in same order as previous table for ease of comparison. 


\section{Appendix B (continued)}

Online Supplemental Materials: Tables

Table B4

Scale Properties in Studies 1 and 2

\begin{tabular}{|c|c|c|c|c|c|c|c|c|c|}
\hline \multirow[b]{2}{*}{ Scale } & \multicolumn{6}{|c|}{ Study 1} & \multirow[b]{2}{*}{ A } & \multirow[b]{2}{*}{10} & \multirow[b]{2}{*}{35} \\
\hline & $M$ & $S D$ & $\mathrm{~F}$ & $\mathrm{P}$ & S & M & & & \\
\hline Food & 22.7 & 5.8 & $(.77)$ & & & & & & \\
\hline Physical & 23.0 & 5.1 & .42 & (.69) & & & & & \\
\hline Social & 28.8 & 4.5 & .23 & .37 & $(.80)$ & & & & \\
\hline Money & 26.5 & 6.1 & .39 & .44 & .25 & $(.88)$ & & & \\
\hline Achievement & 25.6 & 6.0 & .31 & .60 & .37 & .37 & $(.84)$ & & \\
\hline DGI-10 & 35.8 & 6.6 & .58 & .71 & .57 & .62 & .75 & $(.77)$ & \\
\hline DGI-35 & 126.6 & 19.5 & .68 & .79 & .59 & .71 & .76 & .91 & $(.90)$ \\
\hline
\end{tabular}

Study 2

\begin{tabular}{lccccccccc} 
Scale & $M$ & $S D$ & $\mathrm{~F}$ & $\mathrm{P}$ & $\mathrm{S}$ & $\mathrm{M}$ & $\mathrm{A}$ & 10 & 35 \\
\hline Food & 22.5 & 5.6 & $(.74)$ & & & & & & \\
Physical & 22.4 & 5.1 & .43 & $(.69)$ & & & & & \\
Social & 29.4 & 4.3 & .23 & .42 & $(.81)$ & & & & \\
Money & 27.2 & 6.2 & .37 & .50 & .33 & $(.89)$ & & & \\
Achievement & 26.1 & 6.0 & .32 & .56 & .41 & .42 & $(.84)$ & & \\
DGI-10 & 36.3 & 6.7 & .59 & .72 & .58 & .66 & .73 & $(.79)$ & \\
DGI-35 & 127.5 & 19.6 & .66 & .80 & .62 & .75 & .76 & .92 & $(.91)$ \\
\hline
\end{tabular}

Note. $n_{1}=1,900 . n_{2}=7,771 . \mathrm{F}=$ Food, $\mathrm{P}=$ Physical, $\mathrm{S}=$ Social, $\mathrm{M}=$ Money, $\mathrm{A}=$ Achievement, $10=\mathrm{DGI}-10$ short form composite, 35 = DGI-35 composite. Table values are means, standard deviations, and correlations, with alphas indicated in parentheses. 


\section{Appendix B (continued)}

Online Supplemental Materials: Tables

Table B5

Scale Properties in Study 1 by Gender

Females

\begin{tabular}{lccccccccc} 
Scale & $M$ & $S D$ & $\mathrm{~F}$ & $\mathrm{P}$ & $\mathrm{S}$ & $\mathrm{M}$ & $\mathrm{A}$ & 10 & 35 \\
\hline Food & 21.9 & 5.8 & $(.76)$ & & & & & & \\
Physical & 23.9 & 4.9 & .46 & $(.68)$ & & & & & \\
Social & 29.6 & 4.1 & .20 & .35 & $(.76)$ & & & & \\
Money & 26.1 & 6.1 & .38 & .47 & .24 & $(.87)$ & & & \\
Achievement & 26.9 & 5.7 & .32 & .60 & .37 & .38 & $(.84)$ & & \\
DGI-10 & 36.4 & 6.3 & .61 & .71 & .55 & .61 & .74 & $(.75)$ & \\
DGI-35 & 128.3 & 18.7 & .69 & .81 & .55 & .73 & .76 & .91 & $(.90)$
\end{tabular}

Males

\begin{tabular}{lccccccccc} 
Scale & $M$ & $S D$ & $\mathrm{~F}$ & $\mathrm{P}$ & $\mathrm{S}$ & $\mathrm{M}$ & $\mathrm{A}$ & 10 & 35 \\
\hline Food & 23.5 & 5.7 & $(.76)$ & & & & & & \\
Physical & 22.3 & 5.1 & .45 & $(.69)$ & & & & & \\
Social & 28.1 & 4.9 & .30 & .36 & $(.82)$ & & & & \\
Money & 26.8 & 6.1 & .38 & .44 & .28 & $(.88)$ & & & \\
Achievement & 24.4 & 6.1 & .37 & .58 & .35 & .40 & $(.83)$ & & \\
DGI-10 & 35.3 & 6.9 & .59 & .70 & .57 & .63 & .76 & $(.78)$ & \\
DGI-35 & 125.0 & 20.0 & .70 & .78 & .61 & .72 & .76 & .91 & $(.90)$ \\
\hline
\end{tabular}

Note. $n_{\text {female }}=888 . n_{\text {male }}=997 . \mathrm{F}=$ Food, $\mathrm{P}=$ Physical, $\mathrm{S}=$ Social, $\mathrm{M}=$ Money, $\mathrm{A}=$ Achievement, $10=$ DGI-10 short form composite, $35=$ DGI-35 composite. Table values are means, standard deviations, and correlations, with alphas indicated in parentheses. All mean differences by gender are statistically significant $(p<.05)$. 


\section{Appendix B (continued)}

Online Supplemental Materials: Tables

Table B6

Scale Properties in Study 2 by Gender

Females

\begin{tabular}{lccccccccc} 
Scale & $M$ & SD & F & P & S & M & A & 10 & 35 \\
\hline Food & 21.9 & 5.6 & $(.75)$ & & & & & & \\
Physical & 23.4 & 4.9 & .46 & $(.67)$ & & & & & \\
Social & 30.1 & 4.0 & .24 & .39 & $(.79)$ & & & & \\
Money & 27.0 & 6.2 & .36 & .51 & .31 & $(.88)$ & & & \\
Achievement & 27.4 & 5.5 & .32 & .55 & .39 & .41 & $(.83)$ & & \\
DGI-10 & 37.1 & 6.4 & .61 & .73 & .56 & .66 & .71 & $(.77)$ & \\
DGI-35 & 129.7 & 18.9 & .68 & .80 & .60 & .75 & .74 & .91 & $(.90)$
\end{tabular}

Males

\begin{tabular}{lccccccccc} 
Scale & $M$ & $S D$ & $\mathrm{~F}$ & $\mathrm{P}$ & $\mathrm{S}$ & $\mathrm{M}$ & $\mathrm{A}$ & 10 & 35 \\
\hline Food & 23.1 & 5.5 & $(.74)$ & & & & & & \\
Physical & 21.5 & 5.1 & .45 & $(.70)$ & & & & & \\
Social & 28.8 & 4.4 & .27 & .41 & $(.81)$ & & & & \\
Money & 27.3 & 6.3 & .38 & .51 & .34 & $(.89)$ & & & \\
Achievement & 25.0 & 6.1 & .37 & .55 & .39 & .45 & $(.84)$ & & \\
DGI-10 & 35.7 & 6.9 & .61 & .71 & .58 & .67 & .75 & $(.80)$ & \\
DGI-35 & 125.6 & 20.1 & .68 & .79 & .62 & .76 & .77 & .92 & $(.91)$ \\
\hline
\end{tabular}

Note. $n_{\text {female }}=3,578 . n_{\text {male }}=4,142 . \mathrm{F}=$ Food, $\mathrm{P}=$ Physical, $\mathrm{S}=$ Social, $\mathrm{M}=$ Money, $\mathrm{A}=$ Achievement, $10=$ DGI-10 short form composite, $35=$ DGI-35 composite. Table values are means, standard deviations, and correlations, with alphas indicated in parentheses. All mean differences by gender are statistically significant $(p<.05)$. 
Appendix B (continued)

Online Supplemental Materials: Tables

Table B7

Scale Properties in Study 1 by Location

\section{U.S. Participants}

\begin{tabular}{lccccccccc} 
Scale & $M$ & $S D$ & $\mathrm{~F}$ & $\mathrm{P}$ & $\mathrm{S}$ & $\mathrm{M}$ & $\mathrm{A}$ & 10 & 35 \\
\hline Food & 22.6 & 5.8 & $(.77)$ & & & & & & \\
Physical & 23.4 & 5.1 & .42 & $(.70)$ & & & & & \\
Social & 29.1 & 4.5 & .21 & .31 & $(.80)$ & & & & \\
Money & 26.4 & 6.3 & .39 & .40 & .23 & $(.88)$ & & & \\
Achievement & 26.3 & 6.0 & .32 & .57 & .31 & .34 & $(.84)$ & & \\
DGI-10 & 36.1 & 6.7 & .58 & .69 & .55 & .59 & .74 & $(.77)$ & \\
DGI-35 & 127.7 & 19.9 & .69 & .77 & .56 & .70 & .74 & .91 & $(.91)$
\end{tabular}

International Participants

\begin{tabular}{lccccccccc} 
Scale & $M$ & \multicolumn{1}{c}{$S D$} & $\mathrm{~F}$ & $\mathrm{P}$ & $\mathrm{S}$ & $\mathrm{M}$ & $\mathrm{A}$ & 10 & 35 \\
\hline Food & 23.0 & 5.7 & $(.77)$ & & & & & & \\
Physical & 22.4 & 5.0 & .43 & $(.68)$ & & & & & \\
Social & 28.4 & 4.6 & .25 & .41 & $(.81)$ & & & & \\
Money & 26.5 & 5.9 & .38 & .47 & .26 & $(.86)$ & & & \\
Achievement & 24.4 & 5.9 & .32 & .61 & .40 & .40 & $(.82)$ & & \\
DGI-10 & 35.3 & 6.5 & .59 & .72 & .57 & .63 & .76 & $(.77)$ & \\
DGI-35 & 124.7 & 18.8 & .68 & .81 & .60 & .72 & .77 & .91 & $(.89)$ \\
\hline
\end{tabular}

Note. $n_{\text {US }}=1,178 . n_{\text {International }}=695 . \mathrm{F}=$ Food, $\mathrm{P}=$ Physical, $\mathrm{S}=$ Social, $\mathrm{M}=$ Money, $\mathrm{A}=$ Achievement, $10=$ DGI-10 short form composite, $35=$ DGI-35 composite. Table values are means, standard deviations, and correlations, with alphas indicated in parentheses. All mean differences by nationality are statistically significant, except for the Food and Money subscales $(p<.05)$. 


\section{Appendix B (continued)}

Online Supplemental Materials: Tables

Table B8

Scale Properties in Study 2 by Location

\section{U.S. Participants}

\begin{tabular}{lccccccccc} 
Scale & $M$ & SD & F & P & S & M & A & 10 & 35 \\
\hline Food & 22.2 & 5.7 & $(.75)$ & & & & & & \\
Physical & 22.6 & 5.3 & .43 & $(.71)$ & & & & & \\
Social & 29.4 & 4.4 & .25 & .44 & $(.81)$ & & & & \\
Money & 26.9 & 6.4 & .36 & .51 & .35 & $(.89)$ & & & \\
Achievement & 26.8 & 6.0 & .33 & .57 & .44 & .45 & $(.85)$ & & \\
DGI-10 & 36.4 & 6.9 & .59 & .74 & .61 & .67 & .75 & $(.80)$ & \\
DGI-35 & 128.0 & 20.3 & .66 & .81 & .64 & .76 & .77 & .92 & $(.91)$
\end{tabular}

International Participants

\begin{tabular}{lccccccccr} 
Scale & $M$ & $S D$ & $\mathrm{~F}$ & $\mathrm{P}$ & $\mathrm{S}$ & $\mathrm{M}$ & $\mathrm{A}$ & 10 & 35 \\
\hline Food & 22.8 & 5.4 & $(.73)$ & & & & & & \\
Physical & 22.2 & 4.9 & .42 & $(.68)$ & & & & & \\
Social & 29.3 & 4.1 & .22 & .39 & $(.80)$ & & & & \\
Money & 27.4 & 6.1 & .38 & .49 & .30 & $(.89)$ & & & \\
Achievement & 25.3 & 5.9 & .32 & .56 & .38 & .40 & $(.83)$ & & \\
DGI-10 & 36.3 & 6.6 & .59 & .71 & .56 & .65 & .73 & $(.79)$ & \\
DGI-35 & 127.0 & 19.0 & .67 & .79 & .60 & .75 & .76 & .91 & $(.90)$ \\
\hline
\end{tabular}

Note. $n_{\mathrm{US}}=3,747 . n_{\text {International }}=3,903 . \mathrm{F}=$ Food, $\mathrm{P}=$ Physical, $\mathrm{S}=$ Social, $\mathrm{M}=$ Money, $\mathrm{A}=$ Achievement, $10=$ DGI-10 short form composite, $35=$ DGI-35 composite. Table values are means, standard deviations, and correlations, with alphas indicated in parentheses. All mean differences by nationality are statistically significant, except for the Social subscale and DGI-10 scale $(p<.05)$. 
Appendix B (continued)

Online Supplemental Materials: Tables

Table B9

Model Fit and Measurement Invariance Across Study Samples, Gender, and Location

\begin{tabular}{|c|c|c|c|c|c|c|c|}
\hline Constraint & CFI & NFI & RMSEA & sRMR & AIC & $\chi_{\text {S-B }}^{2}$ & $\chi_{\text {S-B }}^{2} / d f$ \\
\hline
\end{tabular}

\begin{tabular}{|c|c|c|c|c|c|c|c|}
\hline \multicolumn{8}{|c|}{ All Participants } \\
\hline 5-Factor & .964 & .962 & .057 & .058 & 18,031 & 17,871 & 32.49 \\
\hline 4-Factor & .958 & .957 & .061 & .065 & 20,797 & 20,645 & 37.27 \\
\hline \multicolumn{8}{|c|}{ Invariance Across Studies } \\
\hline Structure & .962 & .960 & .058 & .059 & 19,374 & 19,054 & 17.32 \\
\hline Loadings & .961 & .959 & .058 & .061 & 19,903 & 19,643 & 17.38 \\
\hline Var-Cov & .961 & .959 & .058 & .062 & 20,020 & 19,790 & 17.28 \\
\hline \multicolumn{8}{|c|}{ Invariance Across Gender } \\
\hline Structure & .965 & .962 & .056 & .059 & 18,033 & 17,713 & 16.10 \\
\hline Loadings & .964 & .961 & .056 & .061 & 18,487 & 18,227 & 16.13 \\
\hline Var-Cov & .963 & .961 & .056 & .069 & 18,716 & 18,486 & 16.14 \\
\hline
\end{tabular}

Invariance Across Location

\begin{tabular}{llllllll} 
Structure & .963 & .961 & .058 & .059 & 24,592 & 24,272 & 22.07 \\
Loadings & .961 & .960 & .058 & .062 & 25,222 & 24,962 & 22.09 \\
Var-Cov & .961 & .959 & .057 & .064 & 25,356 & 25,126 & 21.94 \\
\hline
\end{tabular}

Note. $n=9,671$. CFI $=$ Comparative Fit Index, NFI $=$ Normed Fit Index, RMSEA = Root Mean Square Error of Approximation, $\mathrm{sRMR}=$ standardized Root Mean Residual, AIC $=$ Akaike Information Criterion, S-B $=$ Satorra-Bentler correction, 5-Factor $=$ base model with five factors, 4-Factor $=$ model with four factors, Structure $=$ constrained to have the same factor structure across subsamples, Loadings $=$ constrained to have the same loadings across subsamples, Var-Cov $=$ constrained to have the same variancecovariance matrix across subsamples. 


\section{Appendix B (continued)}

Online Supplemental Materials: Tables

Table B10

Replication of Correlations between DGI Scores, Trait Descriptor Ratings, and Behavioral Tendency Ratings in Study 3

\begin{tabular}{|c|c|c|c|c|c|c|c|}
\hline Measure & $\mathrm{F}$ & $\mathrm{P}$ & $\mathrm{S}$ & $\mathrm{M}$ & $\mathrm{A}$ & 10 & 35 \\
\hline \multicolumn{8}{|l|}{ Trait Descriptors } \\
\hline Moderation & .54 & .24 & .06 & .29 & .35 & .46 & .44 \\
\hline Self-Discipline & .53 & .41 & .20 & .26 & .59 & .68 & .58 \\
\hline Diligence & .51 & .44 & .21 & .37 & .65 & .60 & .64 \\
\hline Conscientiousness & .47 & .36 & .03 & .15 & .56 & .43 & .45 \\
\hline Self-Control & .22 & .24 & .27 & .33 & .20 & .37 & .37 \\
\hline Extravagance & -.08 & -.19 & -.29 & -.63 & -.31 & -.31 & -.46 \\
\hline Immoderation & -.59 & -.07 & -.05 & -.32 & -.35 & -.40 & -.42 \\
\hline Achievement-Striving & .29 & .42 & .23 & .43 & .68 & .59 & .60 \\
\hline Well-Being & .34 & .20 & .21 & .16 & .46 & .41 & .40 \\
\hline Prudence & .15 & .48 & .36 & .32 & .29 & .47 & .46 \\
\hline Patience & .27 & .36 & .43 & .30 & .20 & .39 & .45 \\
\hline Perceived Health & .26 & .07 & .09 & .11 & .34 & .24 & .26 \\
\hline Impulse Control & .43 & .24 & .25 & .14 & .35 & .39 & .41 \\
\hline Rebelliousness & -.20 & -.45 & -.49 & -.34 & -.37 & -.56 & -.54 \\
\hline Agreeableness & .17 & .34 & .49 & .05 & .27 & .46 & .37 \\
\hline Neuroticism & -.21 & -.21 & -.18 & .12 & -.27 & -.27 & -.20 \\
\hline Depression & -.34 & -.19 & .01 & -.02 & -.30 & -.26 & -.24 \\
\hline Anger & -.15 & -.09 & -.29 & -.03 & -.09 & -.25 & -.18 \\
\hline Sensation-Seeking & -.26 & -.55 & -.19 & -.40 & -.30 & -.47 & -.49 \\
\hline Altruism & .10 & .24 & .62 & .04 & .19 & .35 & .33 \\
\hline Anxiety & -.15 & .02 & .01 & .02 & -.05 & -.10 & -.04 \\
\hline Perceived Attractiveness & .35 & .04 & .00 & .11 & .20 & .23 & .21 \\
\hline Somatization & -.01 & .19 & -.02 & -.07 & -.06 & .01 & .00 \\
\hline Comprehension & .22 & .34 & .18 & .26 & .27 & .31 & .37 \\
\hline Excitement-Seeking & .19 & -.31 & -.31 & -.21 & -.04 & -.22 & -.19 \\
\hline Perceived Intelligence & .21 & .18 & .09 & .18 & .11 & .23 & .23 \\
\hline Risk-Taking & .08 & -.28 & -.31 & -.11 & -.08 & -.24 & -.19 \\
\hline Openness to Experience & .02 & .07 & .28 & .05 & .10 & .07 & .15 \\
\hline Machiavellianism & .14 & .03 & -.18 & -.06 & .04 & -.04 & -.01 \\
\hline Extraversion & .05 & -.12 & .10 & -.09 & .23 & .04 & .05 \\
\hline \multicolumn{8}{|l|}{ Behavioral Tendency } \\
\hline Buy unneeded purchases & -.31 & -.32 & -.15 & -.54 & -.29 & -.38 & -.49 \\
\hline Lie or hide the truth & -.12 & -.26 & -.30 & -.25 & -.37 & -.30 & -.38 \\
\hline Pay bills on time & .10 & .17 & .17 & .37 & .37 & .32 & .35 \\
\hline Bend or break the rules & -.19 & -.49 & -.48 & -.43 & -.33 & -.55 & -.56 \\
\hline Eat fast food & -.04 & -.37 & -.22 & .01 & -.12 & -.28 & -.20 \\
\hline Exercise & .33 & .09 & -.14 & -.16 & .33 & .30 & .12 \\
\hline Help other people & -.05 & .30 & .55 & .01 & .26 & .34 & .30 \\
\hline Party excessively & -.21 & -.47 & -.24 & -.29 & -.25 & -.37 & -.42 \\
\hline
\end{tabular}


Drink pop / soda

Smoke cigarettes

Think about sex

Read books

Check financial news

Think about food

Gamble

Discuss intellectual topics

Watch television shows

$\begin{array}{rrrrrrr}.17 & -.03 & -.33 & .02 & -.07 & -.14 & -.06 \\ -.11 & -.30 & -.31 & -.39 & -.37 & -.41 & -.44 \\ -.05 & -.30 & -.27 & -.20 & -.18 & -.29 & -.29 \\ .04 & .48 & .15 & .09 & .23 & .27 & .27 \\ .33 & .16 & -.17 & .04 & .19 & .09 & .16 \\ -.39 & .03 & .09 & -.11 & .09 & -.05 & -.09 \\ -.02 & -.23 & -.33 & -.21 & -.11 & -.27 & -.26 \\ .15 & .08 & -.09 & .16 & .16 & .14 & .14 \\ -.07 & -.06 & -.16 & .05 & -.09 & -.14 & -.09\end{array}$

Note. $n=64 . \mathrm{F}=$ Food, $\mathrm{P}=$ Physical, $\mathrm{S}=$ Social, $\mathrm{M}=$ Money, $\mathrm{A}=$ Achievement, $10=$ DGI-10 short form composite, $35=\mathrm{DGI}-35$ composite. For consistency with manuscript Table 3, items are presented in the same order rather than descending. To facilitate visual inspection, statistically significant correlations are bold $(p<.05)$. 